I N T ER NATIONAL MONETARY FUND

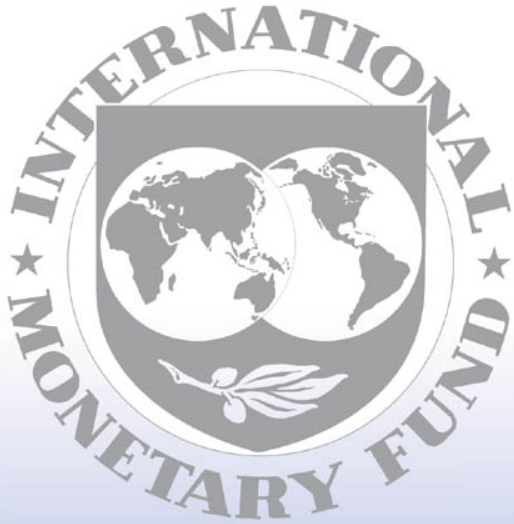

Staff

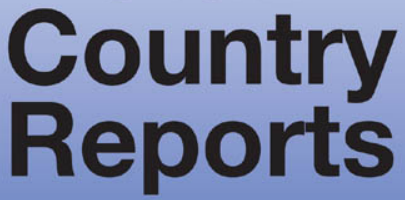


2001 International Monetary Fund

November 2001

IMF Country Report No. 01/207

\section{Italy: 2001 Article IV Consultation-Staff Report, Public Information Notice on the Executive Board Discussion, and Statement by the Executive Director}

Under Article IV of the IMF"s Articles of Agreement, the IMF bolds bilateral discussions with members, usually every year. In the context of a combined discussion of the 2001 Article IV consultation with Italy the following documents have been released and are included in this package:

- the staff report for the 2001 Article IV consultation, prepared by a staff team of the IMF, following discussions that ended on October 9, 2001, with the officials of Italy on economic developments and policies. Based on information available at the time of these discussions, the staff report was completed on October 17,2001. The views expressed in the staff report are those of the staff team and do not necessarily reflect the views of the Executive Board of the IMF.

- the Public Information Notice (PIN) summarizing the views of the Executive Board as expressed during the November 5, 2001, Executive Board discussion of the staff report that concluded the Article IV consultation.

- a statement by the Executive Director for Italy.

The following document has been separately released:

Selected Euro-Area Countries: Rulcs-Based Fiscal Policy and Job-Rich Growth in France, Germany, Italy, and Spain - Report with Supplementary Information

The policy of publication of Article IV staff reports and PINS allows for the deletion of market-sensitive information.

To assist the IMF in evaluating the publication policy, reader comments are invited and may be sent by e-mail to Publicationpolicy@inf.org.

Copies of this report are available to the public from

International Monetary Fund - Publication Services

700 19th Street, N.W. • Washington, D.C. 20431

Telephone: (202) 6237430 - Telefax: (202) 6237201

E-mail: publications@imf.org - Internet: http://www.imf.org

Price: $\$ 15.00$ a copy

\section{International Monetary Fund \\ Washington, D.C.}




\section{INTERNATIONAL MONETARY FUND}

\section{ITALY \\ Staff Report for the 2001 Article IV Consultation}

Prepared by the Staff Representatives for the 2001 Consultation with Italy

Approved by Michael Deppler and G. Russell Kincaid

October 17,2001

Contents

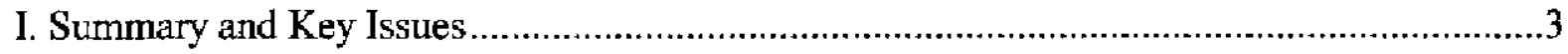

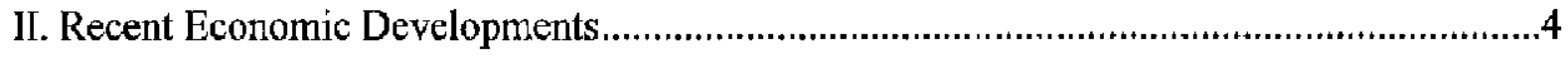

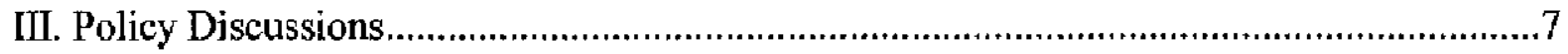

A. The Near-Term Economic Outlook .....................................................................11

B. Fiscal Reform: From Concept to Implementation.........................................16

Tax reform: a cautious start ......................................................................16

Public expenditure: structural reform issues................................................19

Long-run fiscal priorities: quantifying the trade-offs .......................................21

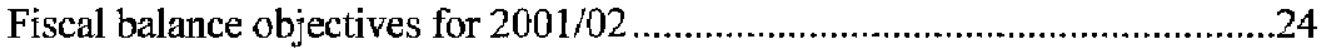

C. Structural Priorities to Enhance Growth ............................................................26

D. Other Issues................................................................................................28

IV. Staff Appraisal .28

Tables

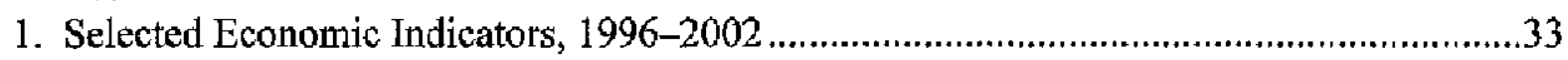

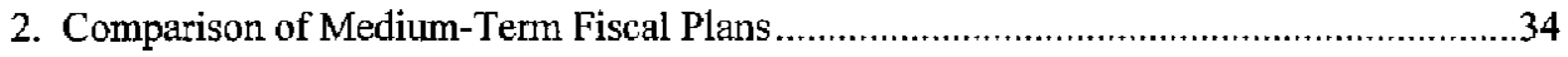

3. Adjustment Measures in the 2002 Budget ....................................................................35

4. Fiscal Developments Under Alternative Scenarios .............................................................36

5. Indicators of External and Financial Vulnerability .............................................................37

Figures

1. International Comparisons of Macroeconomic Performance, 1996-2001 ….....................5

2. Consumption and Investment, 1998-2001 ,...................................................................6

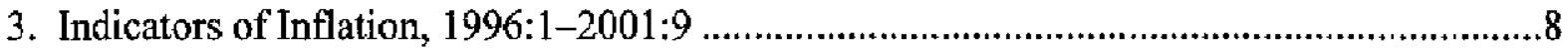


4. Unemployment in Italy and the Euro Area, 1996-2001 …..........................................10

5. Short-Term Indicators, 1996:1-2001:9 ....................................................................

6. External Performance, 1996-2001 …................................................................14

7. Effective Exchange Rates, Selected Interest Rates, and Monetary Conditions Index ........15

8. Fiscal Developments in Italy and the Euro Area, 1996-2001........................................18

Boxes

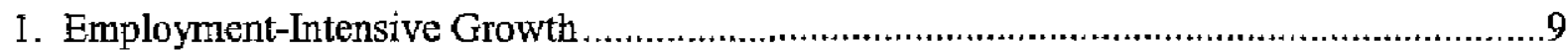

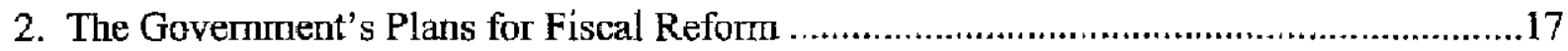

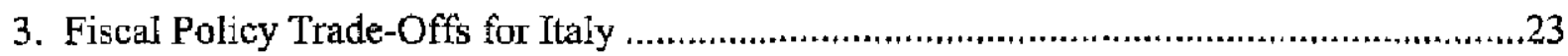

Appendices

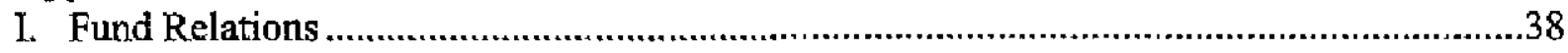

II. Statistical Information .............................................................................................. 


\section{SUMMARY AND KEY ISSUES}

1. Concluding the last Article IV consultation on June 5, 2000, Directors commended Italy's stability-oriented policies, but urged progress on structural issues: the fiscal impact of population aging; the heavy tax burden; and labor and product market performance. These considerations, as well as the agenda of the recently elected government, were at the center of the 2001 consultation discussions, which took place in Rome during July 23-August 3, and during a follow-up visit on October $8-9 .^{1}$

2. Following a decisive victory at the polls, a new coalition government, headed by Mr. Berlusconi, took office in June. Its electoral platform envisaged a sizable reduction of the public sector, deregulation and structural change in the labor and product markets, and an upgrading of public infrastructure--aimed at accelerating economic growth, which has lagged that of Italy's euro partners during the past decade.

3. The discussions, which took place in a setting of weakening growth-and, in October, amid heightened risks following the September 11 attacks in the United States-focused on:

- Near-term fiscal policy: The 2002 budget reconfirms Italy's Stability Program deficit target of 0.5 percent of GDP-despite weaker-than-expected growth, and spending slippages that will likely leave the 2001 deficit somewhat above the original 0.8 percent target. The cut in the deficit in 2002 is more than accounted for by higher revenues from asset sales, with little demand effect; and interest payments are set to decline (relative to GDP). The impact on the economy-under the authorities' growth assumptions-goes beyond the principle of allowing automatic revenue stabilizers to operate and administers a small discretionary stimulus. The authorities agreed that the 2002 budget lacked major fiscal reform steps; and since primary expenditures continue to grow somewhat faster than GDP, the budget does not envisage any significant cut in the tax ratio. They stressed, nonetheless, a commitment to far-reaching reforms of expenditure and taxation--but noted the need for consultation in some areas such as pensions; the impact of spending slippages; and the unexpectedly difficult economic setting.

- Medium-term fiscal issues: The authorities confirmed the Stability Program goal of budget balance in 2003. They wished to achieve measurable progress with tax cuts, while acknowledging that this depends on progress with structural expenditure reforms, including

\footnotetext{
'For Directors' considerations, see http:/www.imf.org/extemal/np/sec/pn/2000/pn0040.htm. The mission-Messrs. Watson (head), Decressin, Kent, Krueger, and Milesi-Ferretti (al] EU1)-met with the Governor of the Bank of Italy; the Ministers of Economy and Finance, Health, Labor, Innovation and Technology, Productive Activities, and Public Functions; senior officials; officers of regulatory agencies and financial market and research institutions; and labor and business leaders. Mr. Padoan, Executive Director, participated in the meetings. Italy's Fund relations are summarized in Appendix I.
} 
in the field of pensions. These objectives were strongly endorsed by the staff. For policy after 2003, priorities were debated, with the staff advising a move into modest surplus-unless structural reforms were so far-reaching as to transform Italy's debt dynamics--but the authorities were more inclined to use interest savings for tax cuts.

- Pollcies to strengthen growth and employment, especially in the South: The authorities have announced the goal of raising Italy's growth rate to 3 percent over the medium term-by enhancing labor market flexibility, cutting the tax burden, streamlining public administration, and upgrading infrastructure in the South. Staff stressed the particular importance of labor market policies, inciuding more regional wage differentiation, training, and tax wedge cuts to facilitate labor market entry--but also counseled caution on the ex ante growth assumptions to be used in framing medium- and long-term fiscal goals.

\section{RECENT ECONOMIC DEVelopments}

4. While decisive progress has been made in embedding macroeconomic stability, the experience with economic growth has been disappointing over the past decade-and the recovery of 1999/2000 proved short lived (Table 1 and Figure 1). Economic growth has considerably lagged the euro-area average-even in 2000 , when the growth rate of close to 3 percent was among the highest in Italy for over 10 years. As explored in more detail during last year's consultation (see SM/00/88, 5/15/00), Italy's poor growth performance over the past decade can be attributed mainly to structural weaknesses, related to the high tax burden on labor income; insufficient wage moderation in earlier years; and only limited progress on labor and product market reform. This has left a legacy of high and regionally

Selected Economic indicators, 2000-01 (Real growth atser, in percent, whics otherwise noled)

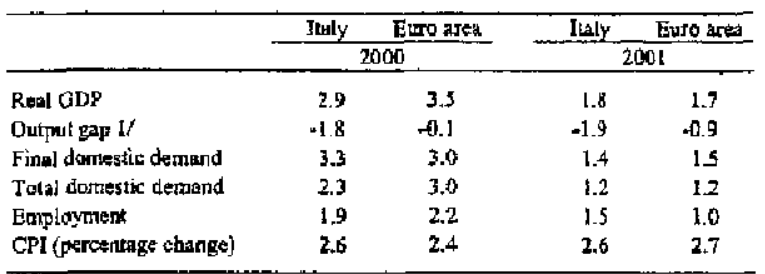

Saurce8: ISTAT; and Fund staff eztimates.

I/ In petcent of potencial GDP. very unbalanced unemployment. And the recent upswing faltered quickly, even though slack remained ample in contrast with some other industrial countries-raising concems about the resilience of the economy to adverse shocks. At the same time, the past decade witnessed strong progress on fiscal consolidation, and on reducing inflation, where the differential relative to the euro-area average has disappeared.

5. In the second half of 2000 , final domestic demand began to decelerate, and weakness in economic activity became more widespread in early 2001. The initial deceleration in demand (Figure 2) reflected in part an unwinding of the stimulus from earlier declines in interest rates (related to adoption of the euro), as well as negative effects on households' disposable income of higher energy

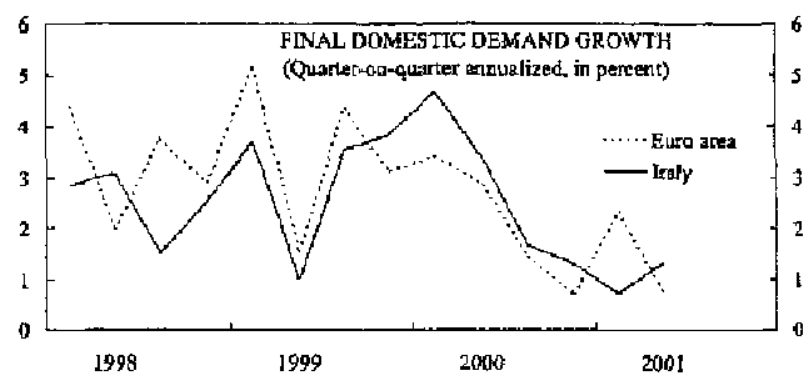


Figure 1, Italy: Intemational Comparisons of Macroeconomic Performance, 1996-2001 1/
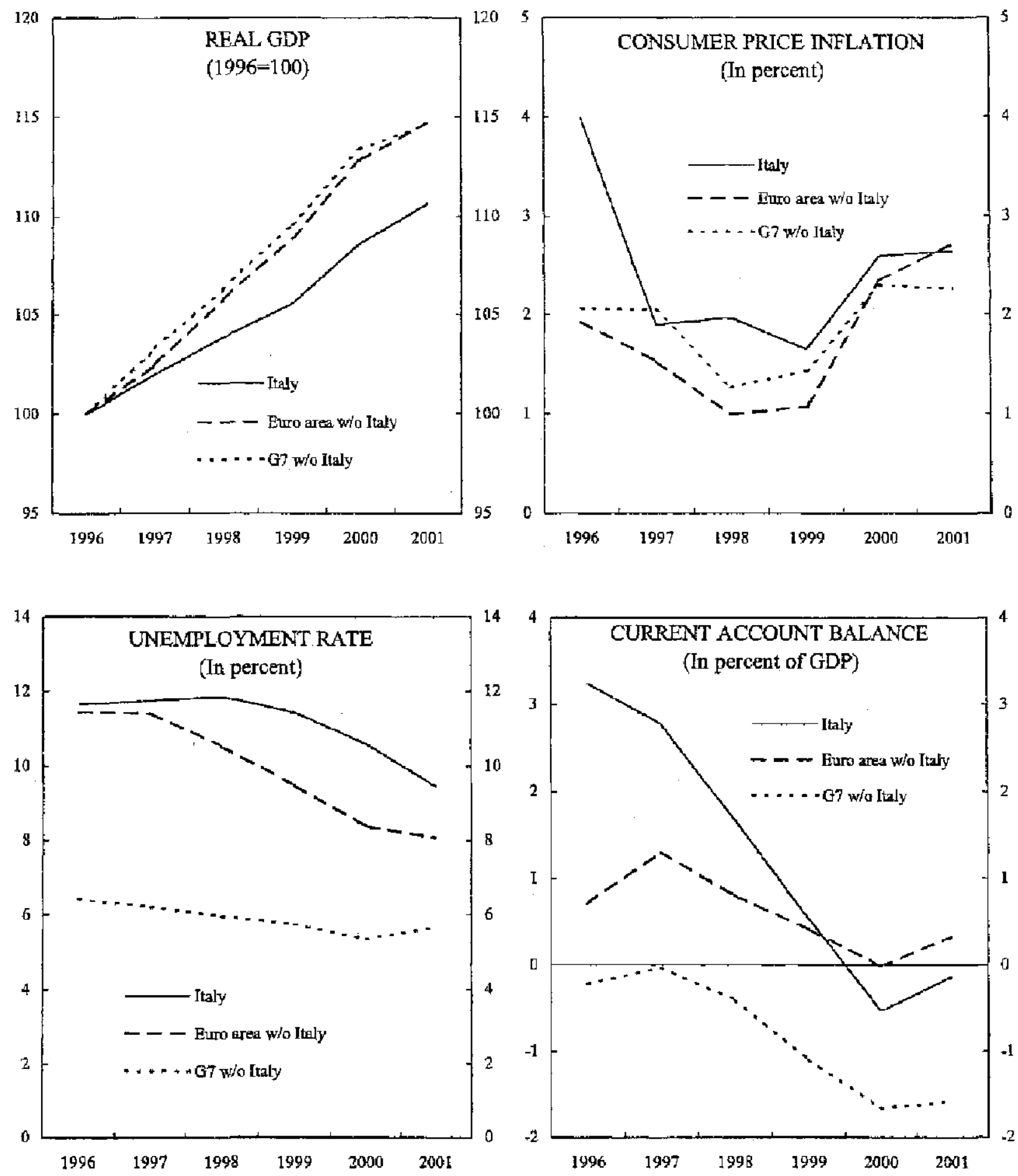

Source: IMF, World Economic Outlook (October 2001).

1/ For Italy, Fund staff estimates for 2001. 
Figure 2. Italy: Consumption and Investment, 1998-2001
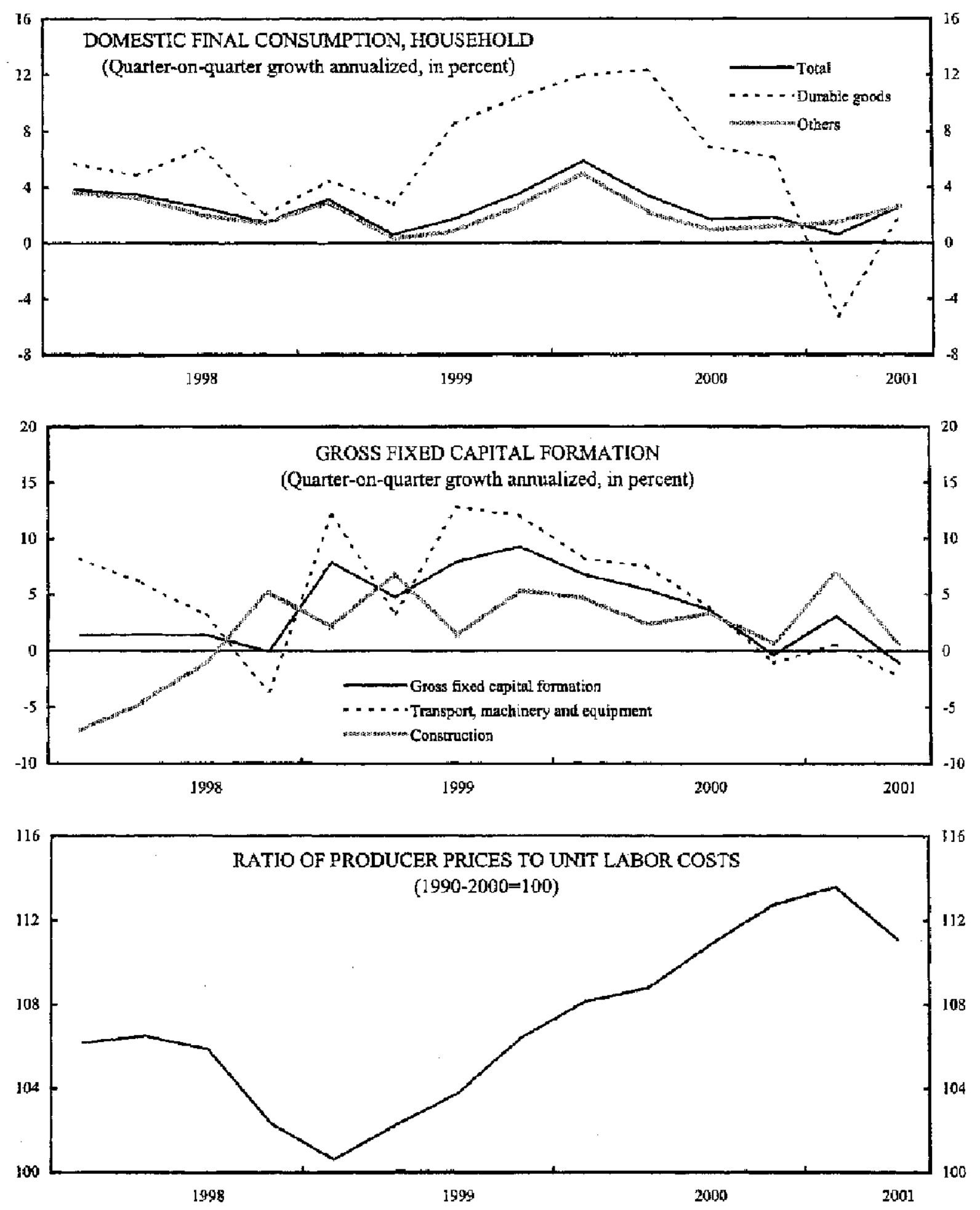

Sources: ISTAT; and Fund staff calculations. 
prices and terms of trade losses. Moreover, weaker external demand led to a sharp deceleration of exports and industrial activity by early 2001; and investment demand slowed in the second quarter, possibly in anticipation of new investment incentives, which were later introduced by the incoming government (see below). As a result, real GDP growthwhich held up in the first quarter of 2001 on account of sizable stock building-stagnated in the second quarter. After an extended period of comparatively slow growth, Italy's output gap, which is estimated by staff at around 2 percent, remains the highest in the euro area.

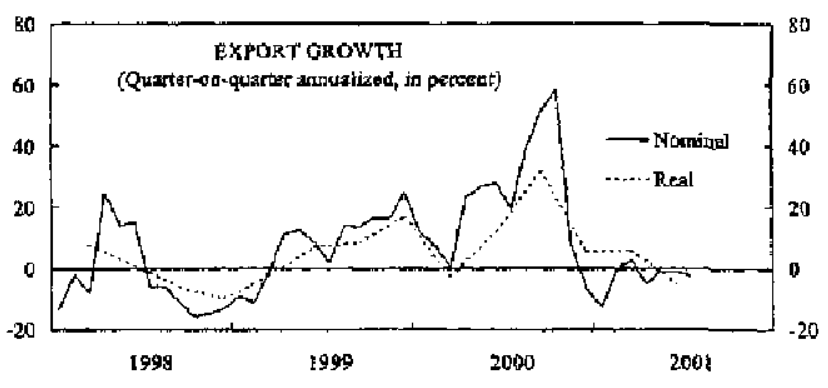

\section{Earlier pressures on headline inflation are abating, and the continuing} moderation of wage increases has supported employment growth. With the retreat in energy prices, harmonized consumer price inflation bas begun to decline, as elsewhere in the euro area- to 2.6 percent (year-on-year) in September after a peak of 3.0 percent in April (Figure 3). An improvement in the inflation outlook is indicated by producer prices, whose level has declined since April. Wage increases, especially in the private sector, remain moderate-avoiding spillovers from higher import prices. And staff analysis (covering the four largest euro-area economies, and discussed in a seminar during the mission) underscores that continuing wage moderation has been crucial in supporting strong job creation in Italy in recent years (Box 1). By July, the unemployment rate feil to 9.2 percent, from 10.1 percent a year earlier. Still, demographic and regional imbalances in the labor market remain pervasive, with unemployment much higher in the South, and among women and the young (Figure 4).

7. Attainment of the $\mathbf{2 0 0 1}$ budget deficit target has been jeopardized by continued expenditure slippages, and these have also adversely impacted the budget for 2002 . Health expenditure slippages, already an issue in 2000, have thwarted achievement of this year's deficit goal of 0.8 percent of GDP; and overruns are also likely on wages, reflecting the level of public pay settlements. Revenues by contrast are on track in 2001, despite weaker-than-projected activity and sizable tax cuts. This reflects improved tax administration, and buoyant direct tax revenues-resulting from strong profitability in 2000 and the high yield from a tax on firms' asset revaluation. Assuming very determined expenditure management and additional asset sales, and subject to the uncertainties discussed below, the authorities and staff are expecting a 2001 deficit of just above 1 percent of GDP. The 2002 budget targets a further decline in the deficit to 0.5 percent of GDP. It thus reconfirms the Stability Program target, but in a setting of considerably weaker growth and with a strong reliance on additional asset sales.

\section{Policy Discussions}

8. The government's reform agenda, which ains to revitalize economic growth, was at the center of the discussions-together with the implications for fiscal policy of the 
Figure 3. Italy: Indicators of Inflation, 1996:1-2001:9

(In percent)
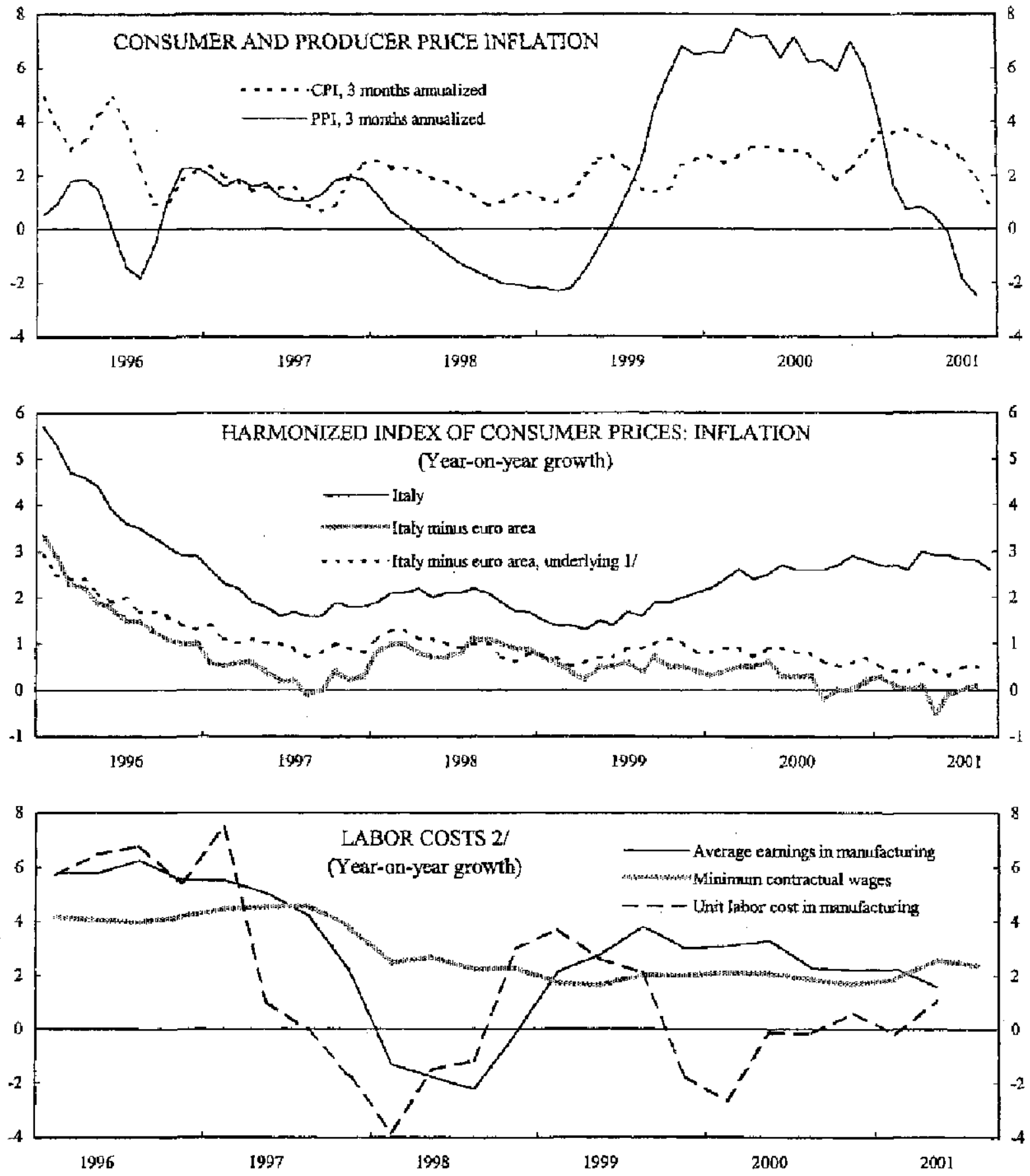

Sources: Bank of Italy; ISTAT; and EUROSTAT.

1/ Excluding energy, food, tobacco, and alcohol.

2/ Data for 1998, which suggest a decline of 1.5 percent in unit labor costs, reflect the removal of various contributions in the context of the introduction of IRAP. If the portion of IRAP revenues attributable to labor is added to wages, labor costs effectively borne by firms increased 2.3 percent in 1998. 


\section{Box 1. Employment-Intensive Growth}

Employment-intensive growth is a striking feature of Italy's economic performance since the mid1990s. This box analyses the relation between employment and output growth during the last decade, drawing on a background paper on Job-Rich Growth in Europe (SM/01/307, 10/5/01, Chapter II).

Employment growth has been sustained during the second half of the $1990 \mathrm{~s}$, despite a broadly unchanged output gap. Measured in employment units (i.e., adjusted for hours worked), employment stands at the level of the previous cyclical peak around the turn of the last decade (see chart). More formal tests reported in the background paper regress employment growth on output growth

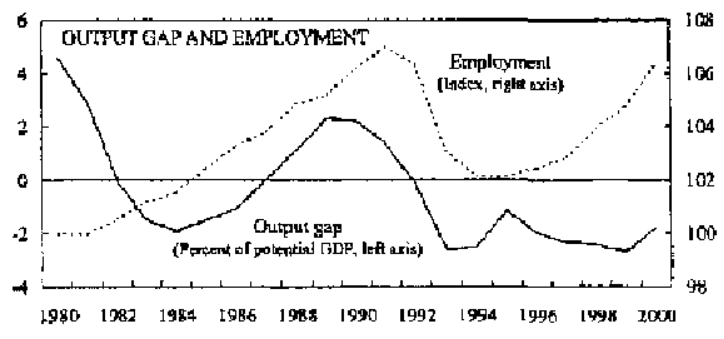
and test for a break in the 1990 s. The results suggest that a 1 percent increase in output raised employment by 0.8 percent in the $1990 \mathrm{~s}$, or twice the rate of the previous two decades.

A sharp moderation in labor cost increases appears to have sustained employment growth, accounting for most of the expansion in the employment intensity of growth. Real compensation of labor deflated by total factor productivity growth (and scaled by the share of labot in total income) declined-particularly since the early 1990 s, and thus later than in France and Spain. But unlike in the other countries, the decline in costs was achieved despite a large increase in payroll taxes, as evidenced by a 10 percentage point drop in the share of wages in total compensation during the $1980 \mathrm{~s}$.
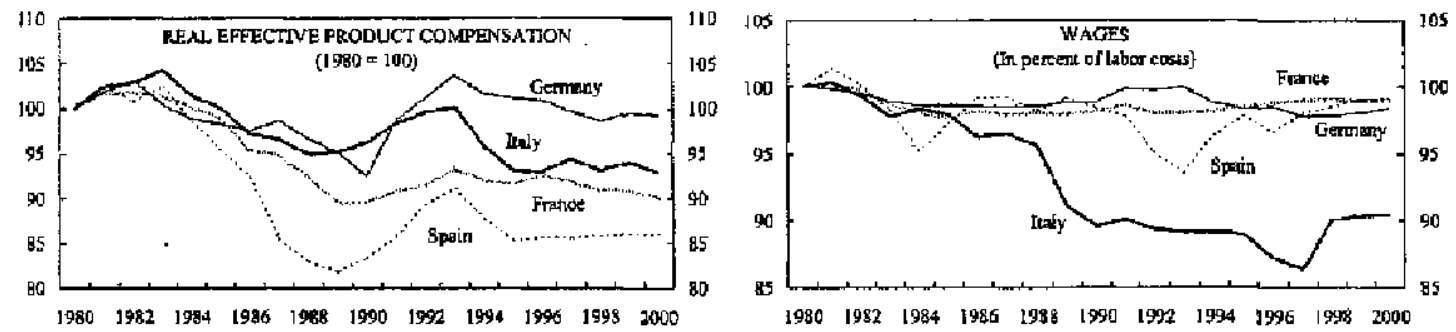

Labor market deregulation has facilitated the response of employment to wage moderation, and possibly also contributed to wage moderation. Particularly noteworthy were the Treu package of 1997, but also further deregulation in subsequent years. By contrast, active labor market policies appear expensive and ill targeted, benefiting largely the Center-Noth, where unemployrnent has remained relatively low. Moreover, the phase-out of morc generous employment subsidies targeted at the South-... conforming to EU regulations- has pushed up labor costs in the South.

The labor market performance differs sharply across regions, with high unemployment in the Sacth failing to lower wages. During 1983-2000, the unemployment rate in the South rose from 150 percent to 350 percent of the level in the CenterNorth. A standard wage curve-relating wages to unemployment rates-would suggest that labor costs (ULC) in the South should have declined by about 27 percent relative to the Center-North in response to rising relative unemployment. In fact, relative labor costs rose in the South

\begin{tabular}{|c|c|c|}
\hline & 1983 & 2000 \\
\hline Unemployment rate & 10.1 & 21.0 \\
\hline In perrent of Center-North & 353.0 & 350.0 \\
\hline ULC in pertert of Center-Noth & 101.4 & 504,5 \\
\hline & \multicolumn{2}{|c|}{1983.2000} \\
\hline Wattathel pent change in UTC & \multicolumn{2}{|c|}{-26.9} \\
\hline Actual thinge in ULC (1983-98) & \multicolumn{2}{|c|}{3.1} \\
\hline
\end{tabular}

Soares: EUROSTAT; national atuhoritis; and Fund saff

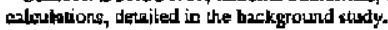

Overall, the evidence underscores the benefits of wage moderation for employment growth. And looking ahead, increased regional, productivity-based wage differentiation may prove essential to lower unemployment. Benefits could also be reaped from further deregulation of the labor market, which has facilitated job entry of the young and a return to the labor market of women. 
Figure 4. Unemployment in Italy and the Euro Area, 1996-2001 (In percent, seasonally adjusted)
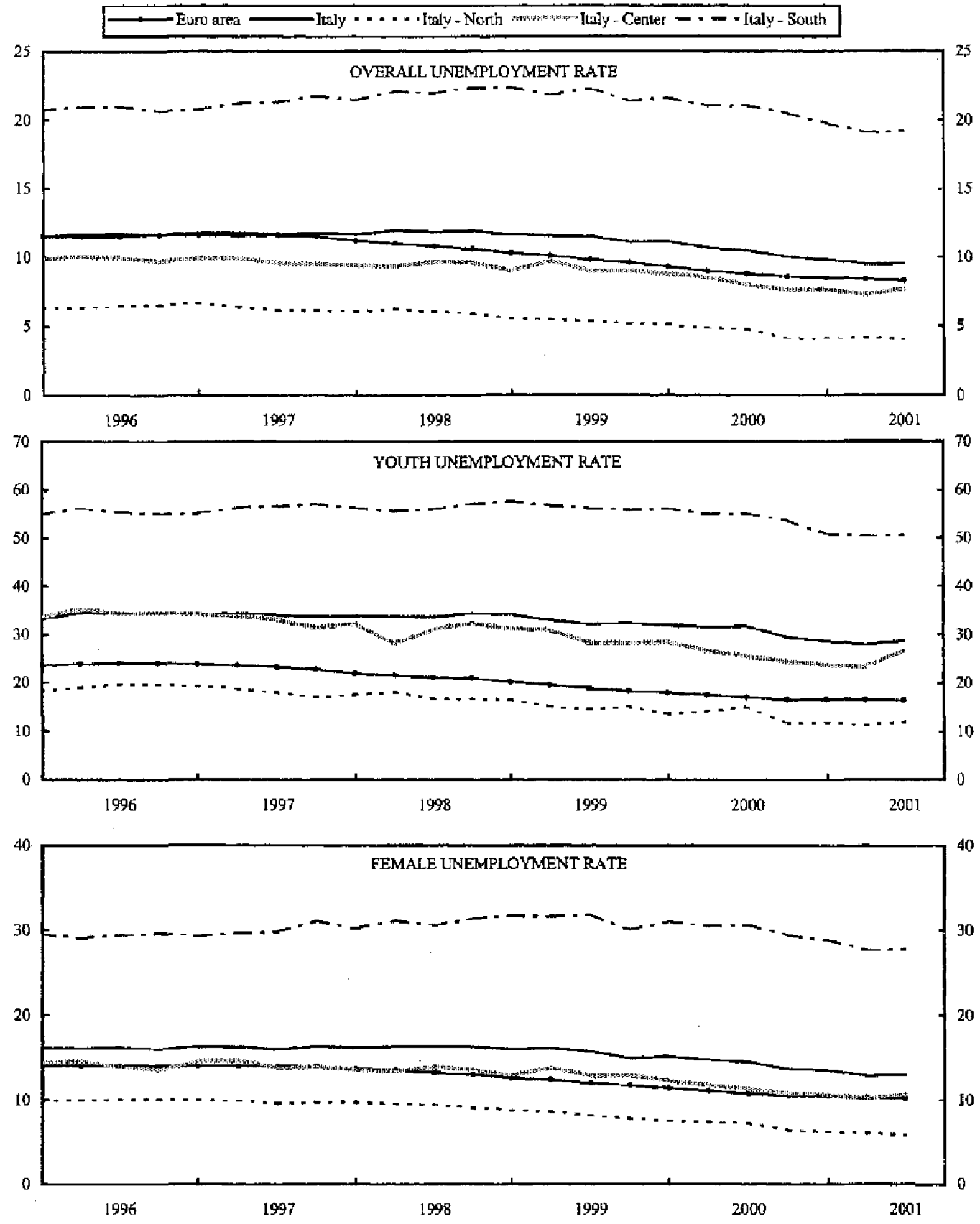

Sources: ISTAT and EUROSTAT. 
global slowdown, with risks heightened by the September attacks in the United States. The program of the new administration envisages a sizable cutback in the public sector, tax reform, progress in the product and labor markets, and infrastructure improvem ents - aiming to revive Italy's decade-long lackluster growth. Achieving this goal is a formidable challenge: it implies, among other things, a narrowing of wide regional imbalances, a substantial increase in Italy's still-low employment level, and an effective approach to the fiscal pressures that stem from a high public debt and rapidly aging population.

9. The economic setting at the time of the discussions-and especially during the follow-up visit in October-added to these challenges, as the likelihood of more extended domestic and global weakness became clearer and risks increased. The staff advised letting fiscal stabilizers operate on the revenue side and proceeding urgently with structural reforms, particularly in public spending - lest the priority of fiscal consolidation, which the authorities have rightly embraced, jeopardize their bold agenda of tax cuts.

\section{A. The Near-Term Economic Outlook}

10. The authorities confirmed during the October staff visit that clearer signs of a slowdown had emerged, and that risks of protracted weakness had risen after the September attacks. Over the summer, a further weakening was evident in most external and domestic indicators (Figure 5). This prompted a reassessment of growth even before the September 11 attacks. Their impact would depend on how quickly the uncertainties - tending to drag down business and consumer confidence-would be resolved, and on the extent and timing of a rebound in the United States. Among the authorities, some saw the Italian economy less vulnerable to the shock than other euro-area countries: Italy's trade (relative to GDP) with the United States was somewhat below the euro-area average; and international financial market linkages and stock market capitalization were lower than for the euro area. Others and staff stressed, however, additional idiosyncratic risks: tourism, a relatively important sector in Italy, was likely to suffer (although it depended only in part on air travel); the country's export product mix included a relatively large share of luxury goods, which may be particularly affected by weakening foreign demand; and a growth rebound in Italy during 2002 depended importantly on the investment effect of temporary tax relief under the so-called "Tremonti-bis" law ${ }^{2}$ - whose impact would become more precarious, if uncertainty and weak business sentiment persist.

11. The staff's new baseline projection, subject to major uncertainties, envisages GDP growth of 1.8 percent in 2001 and 1.4 percent in 2002 - similar to October

\footnotetext{
${ }^{2}$ The "Tremonti-bis" provides temporary, broad-based investment incentives: 50 percent of investment in 2001 and 2002 in excess of average investment during the previous five years is deductible from corporate income taxes. The law covers all firms and independent workers, and it applies also to investment in training and professional development.
} 
Figure 5. Italy: Short-Term Indicators, 1996:1-2001:9
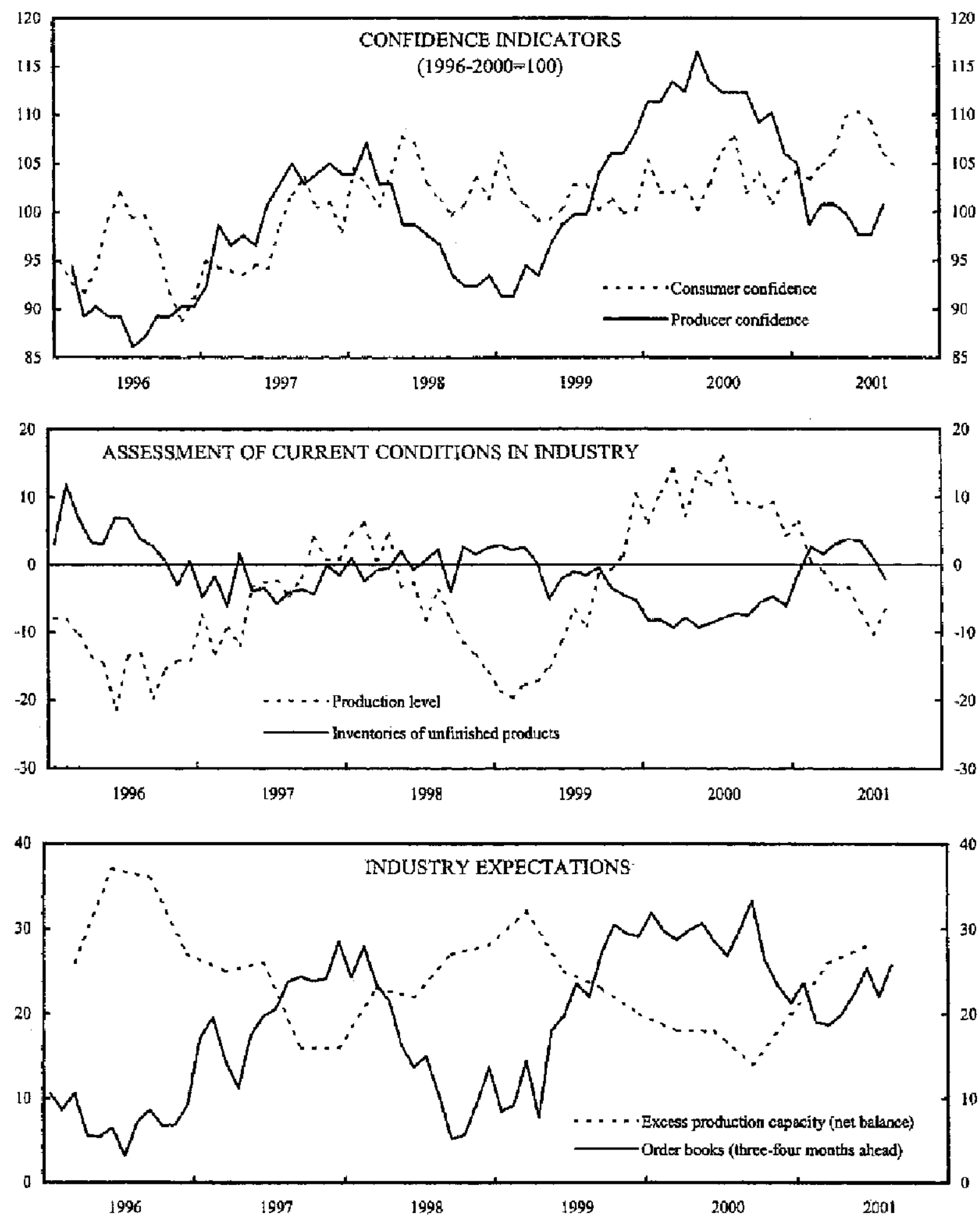

Sources: ISAE; and Fund staff calculations. 
Consensus Forecasts, but for 2002 considerably less sanguine than the budget projection. The staff has marked down Italy's growth prospects broadly in line with that for the other larger euro-area economies. The scenario is not without upside risks-in that employment gains, monetary easing, and lower oil prices could trigger an earlier recovery; but important downside risks also remain, relating especially to external market developments. Those among the authorities who viewed the fallout from the Septernber 1 i attacks as relatively less severe for Italy than other euro-area countries, remained more optimistic than the staff, particularly as regards 2002. And the 2002 budget assumed growth of 2 percent in 2001 and 2.3 percent in 2002 . The authorities acknowledged, however, downside risks to the budget scenario from the September events-to business confidence, the stock market, and possibly consumer confidence. And the impact on Italy could be more pronounced in the case of major exchange rate shifts in competitor countries. ${ }^{3}$

12. In a setting of continuing wage moderation, there was agreement that inflation is set to decline considerably in the period ahead. On wages, discussions with labor union and employer representatives before the September events already pointed to a continued outlook for moderation. This means that the waning of energy and food price pressures will likety be accompanied by a marked decline in inflation through this year and next, to below 2 percent.

13. Competitiveness, underpinned by moderate wage growth, has remained broadly satisfactory - though it is vulnerable to a sharp appreciation of the euro. It is notable that Italy's earlier unfavorable differentials in unit labor cost growth and inflation vis-à-vis its euro-area partners have closed. Nonetheless, the authorities expressed some concern about declining market shares in recent years (Figure 6), and viewed the longer-run outlook for exports as somewhat vulnerable, given their structure-with a marked concentration in goods with relatively low demand elasticities, and subject to increased competition from economies in Central and Eastem Europe. Both the authorities and the staff viewed competitiveness as vulnerable to a sharp appreciation of the euro, which appeared substantially undervalued relative to euro-area fundamentals.

14. Against a background of weakening activity and receding inflationary pressures, the authorities judged that the ECB's interest rate cuts had maintained monetary conditions that were broadly adequate from a domestic standpoint (Figure 7). Bank of Italy staff pointed to the low level of real short-term interest rates, robust growth in bank lending (albeit at rates slightly below those in 2000), the low degree of utilization of credit lines (around 40 percent, well below the average of the 1990s), and the persistent weakness of the euro. On this basis, monetary conditions were not seen as retarding growth. Staff,

${ }^{3}$ Italy was, for example, relatively severely affected by the Asian crisis - partily due to increased third-market competition by those countries after their currencies depreciated. 
Figure 6. Italy: Externał Performance, 1996-2001
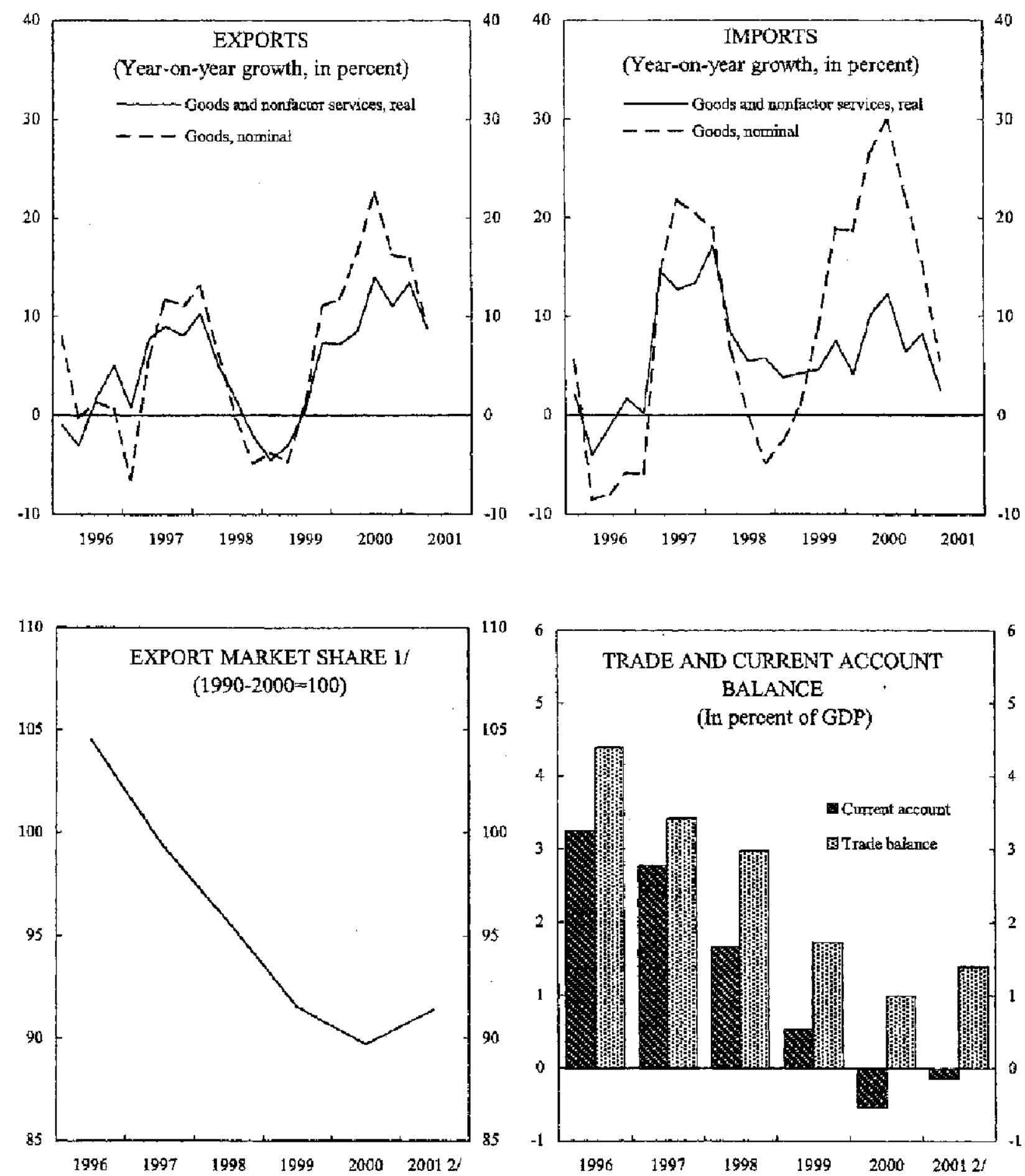

Sources: Bank of Italy, ISTAT; and IMF, World Economic Outlook.

1/ As measured by real growth of exponts of goods and nonfactor services less growth of import demand in partner countries.

2/ Fund staff estimates for 2001 . 
Figure 7. Italy: Effective Exchange Rates, Selected Interest Rates, and Monetary Conditions Index
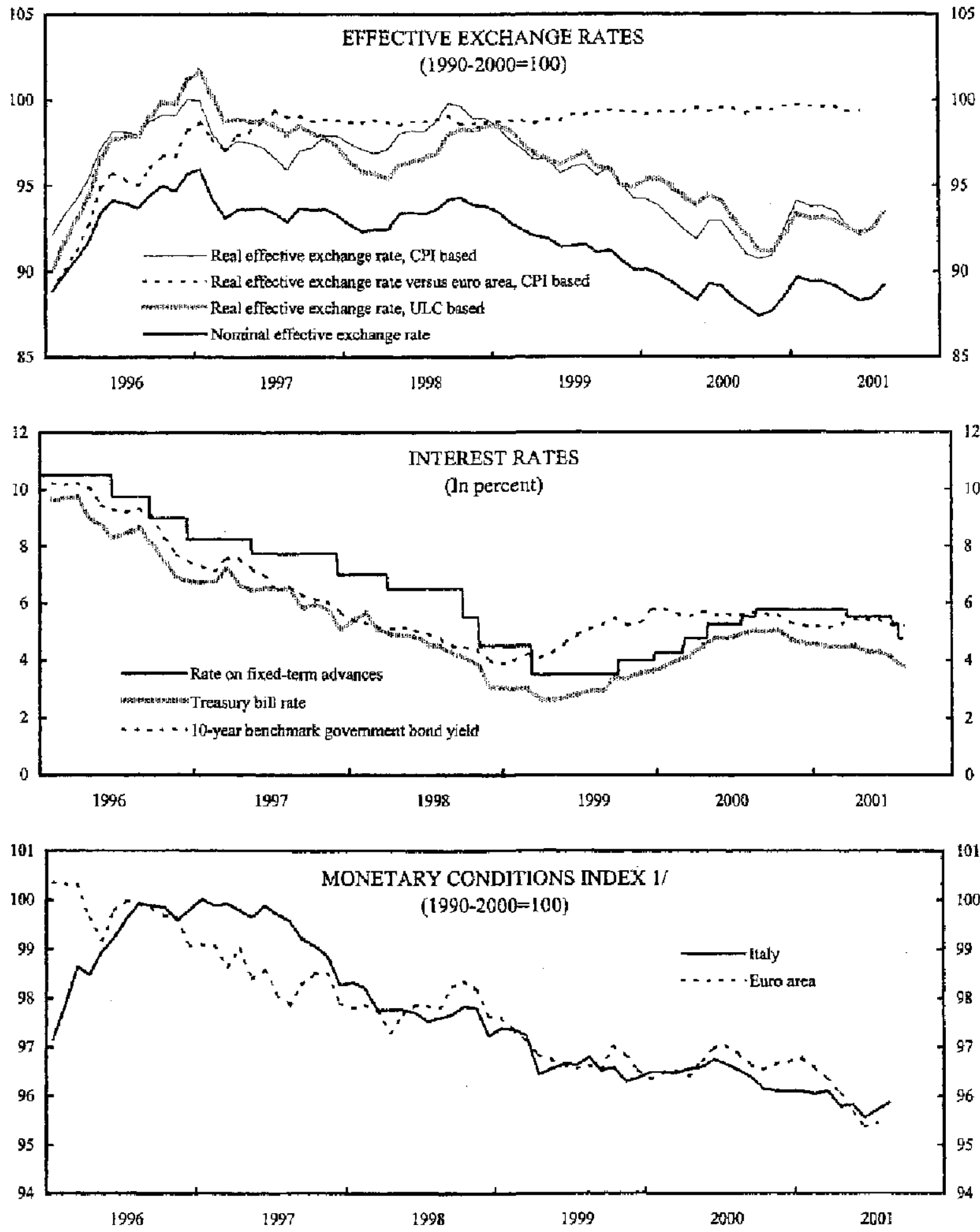

Sources: IMF, International Financial Statistics; Bank of Italy; Bloomberg; and Fund staff calculations.

1/ The index is defined as a weighted average of the real short-term interest rate and the real effective exchange rate, using WEO weights. 
however, viewed conditions as moderately tighter than would be warranted from a domestic perspective, particularly in light of an output gap in Italy considerably above the euro area.

\section{B. Fiscal Reform: From Concept to Implementation}

15. Far-reaching fiscal and public sector reforms were agreed by all interlocutors to be pivotal for the success of the government's strategy. There was a broad consensus on the importance of lowering the tax burden, if not always on the extent and specifics of tax cuts. A debated question was the sequeneing of tax and spending reforms, and possible tradeoffs between tax cuts and medium-term consolidation. With the government in office for only a short time, many aspects of policy implementation remained to be determined, but key priorities were beginning to be fleshed out. At the outset, the authorities allayed staff's concem that fiscal consolidation would take second place to tax cuts; but, with structural expenditure reforms perhaps more challenging than they had anticipated, and subject to consultation with many parties, this left a countervailing risk: the difficulty in pressing forward with the government's planned tax cuts-at least on the original schedule.

\section{Tax reform: a cautious start}

16. The authorities stressed their determination to lower the tax burden in coming years. They envisaged a drastic simplification of the tax system, a reduction in labor and corporate income taxes, and a cut in social security contributions (Box 2 ). In all, the authorities wanted to cut the revenue-to-GDP ratio by some 4 percentage points of GDP by the end of the current legislature in 2006-a reduction more ambitious than planned in most euro-area members, which could push the revenue ratio to well below the area average (Table 2; and Figure 8). Staff welcomed particularly plans to reduce the tax wedge on labor, whose high level was a key factor behind Italy's poor growth performance of the past decade (for an analysis, see SM/00/94, 5/22/00, Chapter I). But staff noted that the sustainability of tax cuts, and hence their long-run effects on investment and growth, would depend crucially on a permanent reduction in the ratio of public spending to GDP.

17. While many measures were yet to be decided, the authorities had nonetheless taken several initiatives during their first days in office, and some further actions in the 2002 budget. Overall, however, they expected no major cut in the tax-to-GDP ratio from these measures - details of which were as follows:

- Temporary tax incentives for new investment (covering 2001/02) were expected by the authorities to yield sizable growth effects, especially in 2002. Staff cautioned that the fiscal costs of the measure needed to be assessed realistically. It also regretted that the new incentives favored debt financing at the expense of the previous, more equitable treatment of different financing sources; and noted that temporary incentives could be distortive. The authorities pointed out, however, that the timing of the incentives had proved fortuitous in view of the economic slowdown-and that they would serve as a bridge before other elements of their strategy came on stream to support investment on a more durable basis. 


\section{Box 2. The Government's Plans for Fiscal Reform}

The plan for fiscal reform of the new government, as discussed in the economic and financial programming document (DPEF), aims to simplify the tax code and substantially reduce the tax burden in general, and direct taxation in particular. The program envisages a balanced budget from 2003 onwards, and targets a reduction in the ratio of current tax revenues to GDP from 42.3 percent in 2000 to 38.2 percent by the end of the legislature in 2006 . Because of the need to balance the budget, the current tax revenue-10-GDP ratio would decline modestly until 2003 (when it would reach 41.5 percent), but rapidly thereafter (see Table 2). The main tax proposals are the following:

- A new "Tremonti law" granting tax incentives on new invesiment and on expenses connected to new hirings:

- Elimination of the inheritarce and "gift" taxes;

- Reduction in the personal income tax brackets to two, with tax rates of 23 percent for incorres below Lit 200 million ( $€ 103,250$ ) and 33 percent for incomes above Lit 200 million. Depending on the structure of the household, incomes below Lit 22 million $(€ 1 \mathrm{l}, 360)$ may be fully tax exempt;

- Gradual reduction in the corporate income tax rate from its current level of 36 percent to 33 percent;

- Gradual elimination of IRAP, a regional tax on value added. Regions would instead be entitled to a co-participation on revenues fiom the corporate income tax;

- Reduction in the rate of social security contributions by I percentage point a year during 2002-06;

- Simplification of the tax code and reduction in the number of taxes to 8 .

The first two measures have already been adopted. The DPEF also noted that the timing for the implementation of other measures may be a function of budgetary outcomes in 2001 . For example, the 2002 budget did not include the first installment of a general reduction in social security contribution rates.

Revenue increases arc expected to come from faster output and employment growth, as well as from an increase in "formal" economic activity (see also paragtaph 17). The authorities' program assumed a GDP growth rate of 3.1 percent from 2002 onwards-mi.e., about twice the average recorded over the past decade-and a decline in unemployment from 9.8 percent in 2001 to 7 percent in 2006.

On the expenditure front, the authorities' plans include measures to upgrade the country's infrastructure, in particular in the South. This public investment program would total Lit 100 trillion (some $4 / 2$ percent of 2000 GDP) over the period 2002-06, 50 percent of which would be financed by the private sector (project financing). In addition, the program proposes a gradual increase in minimum pension payments for "senior and needy citizens." On the expenditure side, the program mentions the need to contain pension expenditure, also through a "liberalization" of the retirement age. In addition, it envisages (i) a reduction in public employment by 1 percent per year, and public sector real wage increases of no more than 1 percent per annura, linked to productivity indicators; and (ii) a privatization program totaling Lit 120 trillion over the next five years.

Overall, current expenditures are expected to decline from 36.7 percent of GDP in 2001 to around 33 percent in 2006, while capital expenditure would remain broadly stable at close to 4 percent of GDP.

Currently incomes under Lit 20 mililion are taxed at a rate of 18 percent, those between Lit 20 and 30 million at 24 percent, those between Lit 30 and 60 million at 32 percent, those between Lit 60 and 135 million at 39 percent, and those above Lit 135 million at 45 percent. 
Figure 8. Fiscal Developments in Italy and the Euro Area, 1996-2001 (In percent of GDP)
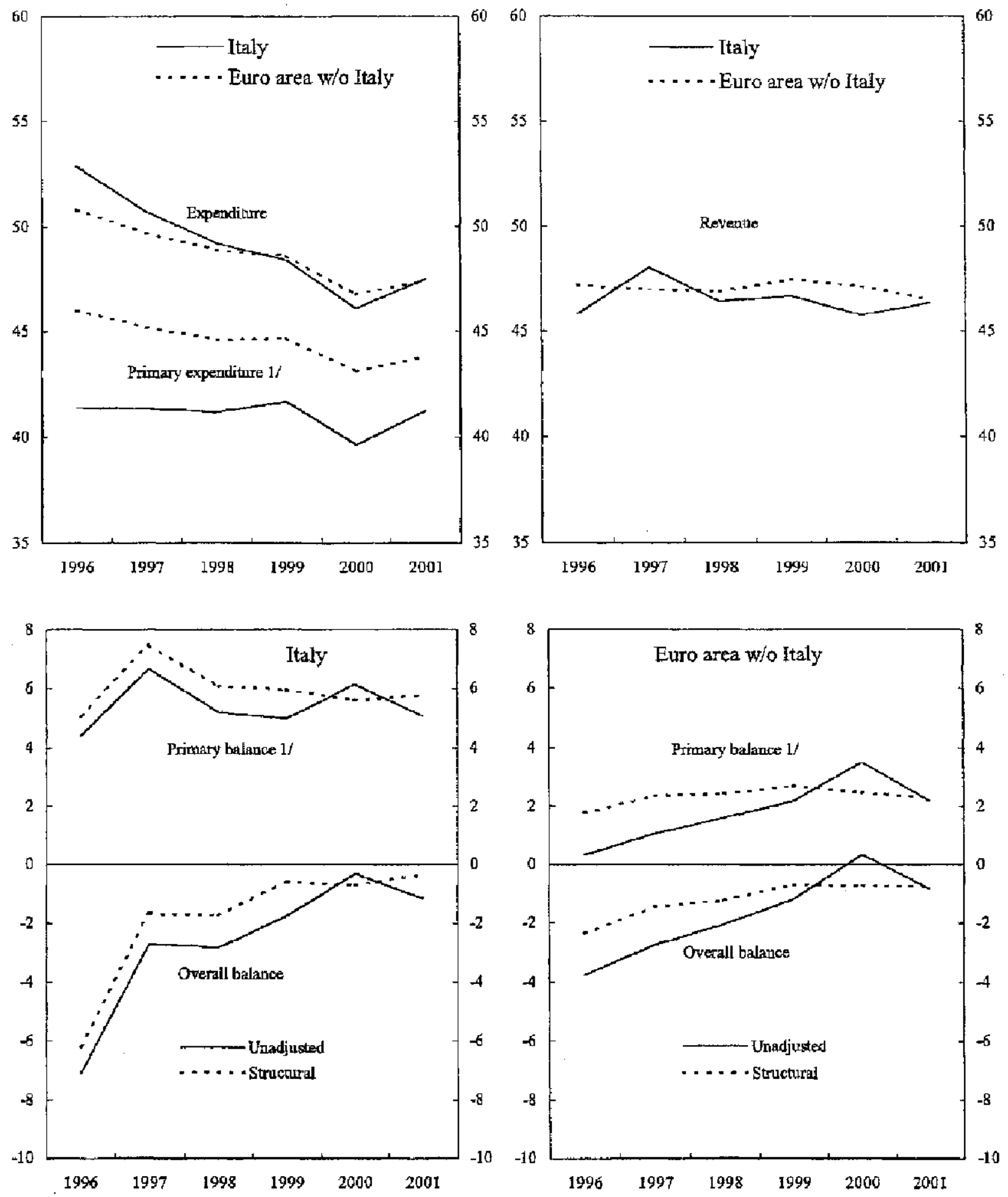

Sources: Data provided by the authorities, with Fund staff calculations; and Fund staff estimates for 2001.

1/ Excludes gross interest expenditure. 
- The measures to bring informal activities into the open included a low initial level of corporate taxes and social contributions for "ẹmerging" firms, and a settlement for past tax and contribution dues. The authorities emphasized that they had very conservatively estimated related revenues for 2001/02. The staff suggested that a significant impact on firms in the underground economy would depend on their being convinced that taxes and regulation would be durably reduced in the future under the government's program - as well as on high penalties for future noncompliance. The authorities agreed. They thought that the initiative provided an attractive option, not least since the informal economy entailed significant costs for firms - such as limited access to formal credit markets and constraints on firm size.

- The abolition of the inheritance and gift taxes would have very small revenue implications. But the authorities saw this as an important signal of fulfilling electoral campaign promises - and it would eliminate a tax that was widely avoided (notably for financial assets).

- Targeted increases of income tax allowances and other tax cuts in the 2002 budget were budgeted to cost some 0.2 percent of GDP-but were more than outweighed by revenue-raising measures (see Table 3 ). The authorities emphasized the social component of the tax reductions in the 2002 budget: tax allowances for low-income families with children are being increased; and tax and social security contributions are reduced to stimulate job creation. Among other measures, however, the budget eliminated the previously planned cuts in personal income tax rates. Overall, the tax burden (in relation to GDP) is targeted to remain broadly unchanged under the 2002 budget.

18. The impact of future tax cuts, the authorities agreed, would depend not only on their overall size and design, but also on their sustainability. This meant a far-reaching reform of public expenditure over the medium term. And while conscious of the difficulties ahead, they were optimistic that they could press through the needed reforms, and get underway with their major program of overall tax cuts in 2003 and beyond. Both tax and expenditure cuts, they stressed, would help stimulate growth-benefiting the public finances over the long run, in combination with other elements of their program discussed below.

\section{Public expenditure: structural reform issues}

19. To make room for tax cuts while respecting EU commitments, the authorities were clear about the need for comprehensive spending reforms: primary expenditure is targeted to decline in their medium-term program by some 4 percentage points of GDP over 2002-06. Discussions focused on action in a number of key areas:

- Public employment. The authorities planned to cut employment at the general government level by 1 percent per annum, starting in 2002 - taking advantage of a turnover rate of around 3 percent. In addition, they planned to curtail public sector real wage increases, while allowing for some productivity-related differentiation. Staff welcomed the prospect that 
past progress in curtailing public employment would be extended forcefully. With increased fiscal devolution, staff noted, strong incentives were especially needed to restrain employment growth at the local and regional levels (a topic further discussed below).

- Public health expenditures. While not high by international standards, and achieving relatively good outcomes, these have increased rapidly in recent years-and overruns have been a major source of fiscal slippage in 2000 and 2001. On pharmaceuticals, slippages this year resulted in part from the abolition of co-payments before the recent election. In August 2001 , mindful of past slippages and demographic pressures ahead, the government moved swiftly to reach agreement with the regions-who are responsible for health care provision, but whose overnuns typically have been covered by the state. The agreement complements Italy's Internal Stability Pact, setting annual ceilings on transfers to regions for 2001-04. Moreover, when regions are responsible for overruns, these will be covered from their own resources (for example, income tax surcharges). In turn, regions enjoy greater autonomy, including for controlling expenditure and limiting demand. Forceful implementation is key for the success of these intergovernmental arrangements. Such arrangements could help break the recent trend increase in health care cost (relative to GDP); but since the agreement aimed to hold health expenditure constant in relation to GDP (at some 6 percent), it would not create room for future tax reductions. The authorities noted the staff's suggestion to reintroduce better-targeted co-payments, and have delayed the abolition of co-payments for certain medical tests.

- Pension reform. A legally mandated review of the impact of the 1995 Dini reform is underway, and a report- by the Brambilla Commission -is being discussed with the social partners. The report notes a need for further steps to contain expenditure, and lays out various reform options. The government is seeking delegated authority from parliament to proceed with reforms-but, in the midst of social dialogue, has not specified precise plans. Like the social partners, it is reviewing options to increase the effective retirement age (not least since life expectancy has increased since the Dini reform); to adjust discrepancies between contribution and payout coefficients; to phase out differences in contribution rates between different categories of workers; and to develop private pension funds, including through the use of severance pay resources - currently under the control of firms. While the demographic shock is one dimension, the authorities also raised the issue that current pension spending may be considered excessive. They saw pension reform as an opportunity to rebalance transfer payments from pensions toward other, presently relatively underdeveloped, social goals. And they noted that pensioners, too, stood to benefit from income tax cuts. The staff, among others, noted the scope to speed up introduction of the contributions-based system (currently applied only to workers with less than 23 years of contributions).

- Subsidies and tax expenditures. The authorities intended to undertake a thorough review. It would cover, inter alia, active labor market policies-which, staff noted, mainly benefited workers in the North, where conditions were much more favorable than in the South. Discussions also addressed the issue of tariffs and cost recovery for the postal service and railways where, progress notwitbstanding, subsidies remain among the highest in Europe. 
20. The need to strengthen Italy's medium-term expenditure framework was a majer focus of the discussions. The staff pressed the case for medium-term expenditure ceilings, which would operate within the guidelines of the Stability and Growth Pact. ${ }^{4}$ Based on longer-term goals for the tax burden and the fiscal balance, these would facilitate a more strategic approach to expenditure reduction and management. At the same time, automatic stabilizers could play fully on the revenue side (and expenditures, in Italy, are in fact largely insensitive to the cycle). To enhance credibility, and reap full benefits of the authorities' fiscal strategy, a medium-term expenditure strategy should encompass all general government spending-relying as necessary on the mechanisms of an enhanced Internal Stability Pact.

21. The authorities broadly welcomed these suggestions, but more steps are needed for their implementation. They thought that the new medium-term agreement with regional govemments represented a step in this direction. And the Minister of Economy and Finance initiated a dialogue with spending ministries on multiyear expenditure ceilings and reform priorities. Staff noted that this approach could prove useful for confronting planned tax reductions with the need for corresponding, well-specified cutbacks on the spending side. It regretted that the 2002 budget did not respect the expenditure ceiling implied by the authorities' previous plans: primary expenditure overruns of some 1/2 percent of GDP in 2001 were carried forward into an upward adjustment of the 2002 expenditure target. Staff also noted that the government's new medium-term program included no explicit expenditure targets. The authorities are, however, considering such targets for future updates of the Stability Program. They were deeply convinced that expenditure reform, while difficult, is the key not only to tax cuts but to changing the longer-run outlook for growth and for the dynamics underlying the public finances

\section{Long-run fiscal priorities: quantifying the trade-offs}

22. The authorities confirmed Italy's Stability Program commitment to balancing the public finances by 2003, but in other respects were exploring trade-offs between alternative fiscal strategies. Staff strongly welcomed the commitment to budget balance, assuming the economy expands broadly as staff projects. ${ }^{5}$ Debate focused on the potential depth and timing of tax cuts, and on how to achieve sustainability in the public finances over the long run, while fostering stronger growth. Several key trade-offs were involved:

- First, a trade-off on the timing of reforms-between going for early, deep expenditure cuts or delaying the government's tax reduction strategy. The authorities' initial plans had

\footnotetext{
${ }^{4}$ See the background paper "Rules-Based Fiscal Policy and the Fiscal Framework in France, Germany, Italy, and Spain." It was presented in a seminar during the consultation discussions.

${ }^{5}$ It would imply a structural primary surplus in 2003 above 6 percent of GDP-a goal previously endorsed by the staff, for reasons relating to public debt dynamics (see below).
} 
called for sizable and early tax cuts, as well as a balanced budget in 2003. Staff stressed the quantitative implications: either upfront entitlement reforms would need to be deep enough to affect the immediate course of social transfers substantially, or discretionary primary spending would have to contract sharply in nominal terms during the next five years (see the "tax cuts/no entitlement reform scenario" in Box 3). The authorities were moving toward a consultative and more gradual strategy, particularly as regards pensions (and on health care, their reform, while achieved quickly, will not cut spending relative to GDP). The staff was concerned that delay, while favorable for consultation, not lead to a loss of momentum as regards the structural measures needed both to underpin tax cuts and to enhance the long-run outlook for the public finances. But, given Italy`s high debt, demographic outlook, and EU commitments, staff agreed on the priority of moving rapidly to achieve budget balance.

- Second, beyond budget balance, a longer-mun trade-off of tax reductions against surpluses-in part a question how far to count on the supply-side impact of tax cuts in addressing debt dynamics. On current policies, Italy's public debt would likely rise rapidly once aging-related fiscal pressures emerge-as illustrated in the staff's "baseline scenario" (for this, and the authorities' somewhat more sanguine projections, see Box 3; and Table 4). To address this challenge, the authorities stressed the role of tax cuts in fostering stronger growth. Rather than running a surplus after 2003 , they would use interest savings to lower the tax burden. Staff also anticipated a "growth dividend" from expenditure, tax, and labor market reforms - and saw filly the attractions of a policy strategy centered on entitlement reforms. But staff cautioned against counting on the benefits until measures had been implemented - and, in the case of the growth dividend, before it transpired. Moreover, absent very far-reaching entitlement reforms, a balanced budget could still leave the public debt well above the Stability and Growth Pact's reference value of 60 percent of GDP at the start of the next decade, when the heaviest impact of population aging sets in (see Box 3: "tax cuts/no entitlement reform scenario"). It would then be necessary to reverse tax cuts to prevent a rise in the debt ratio. Staff urged planning on a structural primary surplus of over 6 percent of GDP after 2003-implying a gradually rising, though modest, overall surplus (see Box 3: "reform scenario"). This would cut the debt ratio to 60 percent in about a decade, and leave a cushion to sustain tax cuts even at the peak intensity of population aging

\section{Discussing these trade-offs, some convergence in views emerged-based in} particular on the pivotal role of structural expenditure reforms. Such reforms were agreed to be key both for the move to budget balance and, beyond that, to open up scope for deeper tax cuts and, possibly, smaller surpluses. For staff, it was too early to judge what progress will be achieved in this area. The authorities-while confident of achieving major spending reforms over time--had decided to take a cautious approach to reducing the tax burden in 2002, given existing fiscal slippages and discussions still underway with the social partners. And on the question whether surpluses are called for after 2003, any definitive view again depends to some degree on the outcome of current discussions on pension reform. 
This box discusses three alternative medium- and long-run fiscal policy scenarios for Italy. These scenarios iliustrate the constraints that the country faces-the level of public debt, the size of pension outlays, and demographic trends-and the trade-offs that these constraints imply, For example, early credible steps to alleviate these constraints conld pave the way for somewhat less ambitious targets for the budget over the medium term.

The room for maneuver on the fiscal frant is circumscribed by a set of factors that, taken together, are considerably tighter for Italy than for most advanced economies: a very high public debt (above 100 percent of GDP); one of the most adverse population-aging trends among advanced economies; a public pension system with presently the second bighest outlays in the OECD (141/2 percent of GDP and essentially no assets); and one of the lowest potential growth rates - with staff estimates reflecting in part the aging trends, but also structural factors. Staff estimates indicate that, absent further reform, aging-related expenditures in Italy would rise by some 6 percentage points of GDP over the next 35 years ( 4 percent due to pension and 2 percent to health care expenditure). The "baseline" Scenario 1 (see charts below; and Table 4) illustrates the implications of these trends, assuming large asset sales in 2002 and 2003 , a stable revenue-to-GDP tatio (net of asset sales) from 2001 onwards, and no policy change on the expenditure side.
Fisoal Policy Constraints in Selected Countries

\begin{tabular}{|c|c|c|c|c|}
\hline & Italy & Prance & Germany & $\begin{array}{l}\text { Uniled } \\
\text { States } \\
\end{array}$ \\
\hline Public pension expenditure in $2000 \mathrm{l} /$ & 14.4 & 12.1 & 9.7 & 4.4 \\
\hline $\begin{array}{l}\text { Old-age dependency ratio in } 2040 \\
\text { (ndex, with } 2000=100 \text { ) }\end{array}$ & 221.5 & 184.1 & 210.7 & 183.5 \\
\hline Gemeral gowermment, net debt in $2000 \mathrm{l}$ & 104.4 & 48.6 & 51.5 & 43.9 \\
\hline
\end{tabular}

Saures: OECD (2001) for peusion expendibure; Viseo (2001) for old-age depenfency ratio; and WEO.

$1 /$ In percent of GDP.

The government's fiscal program for 2002-06 envisages a balanced budget and substantial tax reductions from 2003 onwards. As the authorities recognize, major expenditure reform as well as a strong acceleration of growth are necessary in order for the proposed tax cuss to be sustainable. This point is illustrated in the "tax cuts/no entitlement reform" Scenario 2 : absent entitlement reform and using the staff growth assumptions, the proposed tax cuts would require a drastic reduction in discretionary spending, which would decline in nominal terms during the period 2002-06 (see Table 4). Furthermore, if the budget were to remain in balarce after 2006 (rather than moving into surplus) Italy's debt burden would still be over 70 percent of GDP by 2011 . Tax reductions and structural reform would spur growth and alleviate the public finance constraints, but even a growth rate above 3 percent for the next decade would leave the debt to GDP ratio well above the 60 percent of GDP reference level of the Stability and Growth Pact (SGP) in 10 years' time (Table 4). Given the unfavorable demographics, and no reform of aging-related spending, the commitments under the SGP would then require reversing the tax cuts so as to reduce public debt toward the 60 percent reference level (see charts below).

The staff illustrated a brogd-based strategy, centered on three planks: entitIenent reform, a more modest reduction of the tax burden, and a small budget surplus from $2004 \mathrm{onwards}$. This strategy, ithastrated in the "reform" Scenario 3 (see also Chapter 2 of SM/00/94, 5/22/00) would ensure a substantial reduction of the public debt during this decade, ahead of the most adverse aging impact. It assumes: (1) a permanent reduction in the revenues-to-GDP ratio by 1.8 percentage points between 2000 and 2004 , in line with the Stability Programs in euro-area partner countries; (ii) pension and health reforms to limit the rise in aging-related future outlays; (iii) a structural primary surplus above 6 pereent to reduce public debt below 60 percent of GDP by 2011 . In the long run, this strategy would accommodate a moderate increase in aging-related expenditure during the most adverse demographic period (2010-35) through a weakening fiscal position (with a concurrent further decline in taxes). Indeed, relative to the "boseline," the "reform" Scenario 3 would entail a lower tax burden in the medium tun and especially in the long run (see chart below), in addition to lower primary expenditure.

There are some trade-offs between more ambitious expenditure reforms than envisaged in the staffs scenario and a smaller budget surplus. However, this will require decisive steps to permanently lower primary expenditure-botb discretionary and agerelated, to avoid having to raise taxes again by the next decade.
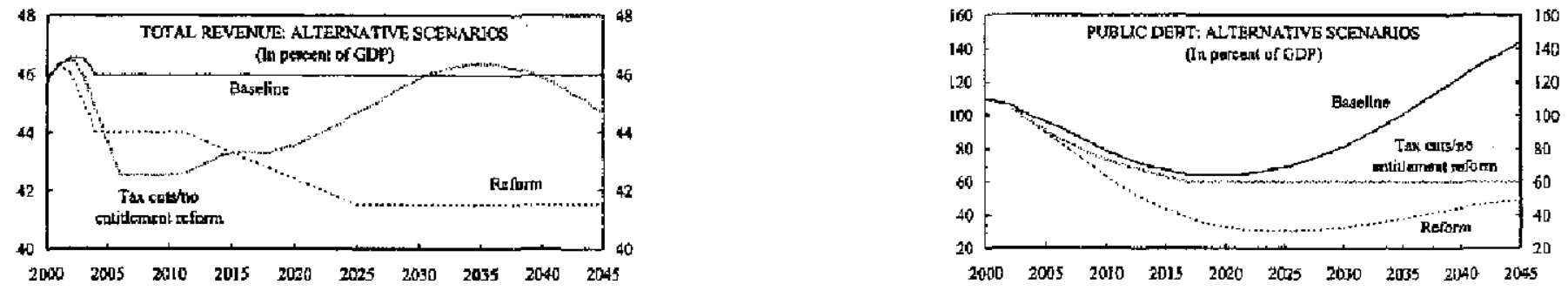

${ }^{1}$ Studies by the Treasury point to smaller pension-related spending increases than projected by staff. These studies-some undertaken under the aegis of the OECD-w-envisage about a 2 percent of GDP "baseline" increase for pensions (versus the staff's 4 percent; see Treasury, 2000). The main differences concern the assumptions about labor productivity growth and labor force participation: urider one scenario, the OECD projects the same labor productivity growth as the staff but an increase in the ratio of employment to (20 to 64-year old) population from presently 57 percent to 88 percent (staff: 62 percent). In another scenario, the OECD assumes higher Jabor productivity growth (1.8 percent versus 1.2 percent by the staff) and an increase in the employment ratio to 66 percent. 
Fiscal balance objectives for $2001 / 02$

24. Turning to policy in 2001 and 2002 , the first challenge proved to be arriving at robust baseline projections for the general government position. At the time of the July mission, estimates of the deficit for 2001 were hotly debated - ranging as high as $23 / 4$ percent of GDP. The wide uncertainty reflected in part a recently widening divergence between different deficit measures-notably, between accruals and cash-based deficits, but also between different cash-based deficit estimates (see chart). While part of the discrepancy was clearly identified-for example, rising cash refinds of taxes-the issue warrants further review, including notably its

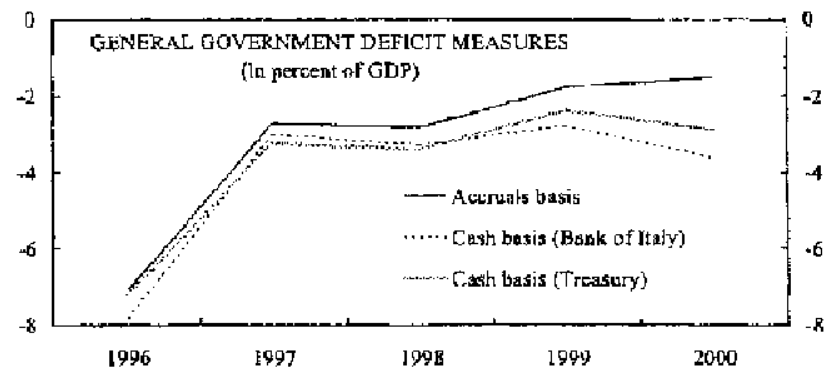
potential implications for future public debt dynamics. This subject will be addressed as part of a fiscal Report on the Observance of Standards and Codes, which the authorities have initiated. Concerning the outturn of the 2001 deficit (on a Eurostat accounting basis), the authorities shared, at the end of the discussions in August, the staff's assessment that decisive expenditure control over the remainder of the year, including at the regional level, could limit the deficit to 1.5 percent, but that this levelalmost twice the original target — would be excessively high.

25. Discussions on 2001/02 then focused on how to mesh consolidation commitments with concerns about the weakeoing ecouomy - and also on the scope for tax cuts. The authorities were sympathetic to the general proposition (elaborated in the euro-area staff report, SM/01/289, 9/24/01) that automatic stabilizers be allowed to operate on the revenue side-while maintaining budgeted expenditure levels. They agreed, however, that italy's tribulations related mainly to expenditure slippages in 2001 , notably on regional health care and wages. Revenues, structurally stronger than anticipated, were broadly on target. To limit deficit overruns in 2001, expenditure management had been tightened, inchuding through the new agreement with regions; a 10 percent across-the-board cut in central government administrative budgets was imposed for the rest of the year; and financial operations and real estate asset sales were under preparation.

26. Overall, there was agreement that budget execution in late 2001 should strive to tightly limit any deficit overruns, including through measures with a small or negligible demand impact. During the July mission, staff bad suggested bringing forward some structural expenditure measures, thereby enhancing the credibility of the authorities' reform agenda. Staff shared, however, their concern of avoiding an unduly negative fiscal impulse over the remainder of the year. In this regard, the authorities' intention to rely in part on measures with low demand effects - such as asset sales, which would facilitate a more productive use of the assets and reduce the gross public debt-seemed prudent. With these measures being implemented, the 2001 deficit can probably be contained at just above 1 percent of GDP, as envisaged in the 2002 budget. But staff stressed that asset sales, while 
presumably reducing the deficit under Eurostat rules, needed to be replaced in time with durable measures, as the output gap narrowed.

27. For 2002, the draft budget placed priority on meeting the Stability Program's deficit target of 0.5 percent of GDP-relying on asset sales and lower interest expenditure, while eschewing major cuts in expenditure or taxation. The authorities stressed that the budget had been drawn up under tight constraints: a commitment to the Stability and Growth Pact; a worse fiscal situation than they had anticipated before entering office--meeting the deficit target required net measures of over 67 billion ( 0.7 percent of GDP; see Table 3); and a weakening of the economy, which called for avoiding fiscal withdrawal. The latter was in part addressed by a further reliance on asset sales and other financial operations- with capital revenues to rise by 0.7 percent of GDP, that is, by somewhat more than the targeted reduction in the fiscal deficit. ${ }^{6}$ The budget would also benefit from a 0.3 percent of GDP decline in interest payments. In addition to weaker-thanprojected growth, the staff saw some risks to meeting the deficit target: the underlying trend deficit could be larger than assumed in the budget; and asset sales may not yield the budgeted revenues. ${ }^{3}$ As concerns far-reaching tax and expenditure reform, the authorities explained that the bealth care financing reform had been successfully put in place, but that more time was needed for a consultative approach and the design of effective reforms in the field of pensions. Still, they pointed to progress on their social agenda, through targeted tax reductions (discussed above) and an increase in minimum pensions.

\section{The staff welcomed the fact that the} 2002 budget aimed for further deficit reduction and took into account the weakening economic situation-but queried the extent of the asset sales and the paucity of expenditure reforms. The authorities shared in principle the staff's view that, under presently plausible macroeconomic scenarios, there was no case for a discretionary fiscal stimulus in Italynot least in view of its bigh public debt. Staff noted, however, that the 2002 budget implied a

${ }^{6}$ Higher capital revenues would mainly relate to real estate sales, with state-owned real estate being transferred to a new entity ("vehicle"). The legal framework is designed to ensure that payments by the vehicle for the assets would reduce the Eurostat-based deficit.

${ }^{7}$ As a technical assumption, the staff's fiscal projections for 2002 below and in the tables are based on the authorities" estimates for the trend deficit and the yield of the 2002 budget measures-adjusted for differences in the macroeconomic framework and interest rates (staff's projections for the latter are broadly similar to the budget assumptions). 
weakening of the structural primary surplus, net of asset sales, on the authorities' growth projections (see text table): since these sales bad little demand effect, the budget would go beyond allowing the full play of the automatic fiscal stabilizers. ${ }^{8}$ The authorities did not dispute this view, but pointed to the sizable budgetary measures already needed to correct a worsening trend deficit (see Table 3). And to bridge the period until more far-reaching expenditure reforms were implemented, they deemed it advisable to rely on asset sales to close the remaining gap vis-à-vis the Stability Program's objective. Staff accepted the use of assets sales, but argued that the underlying fiscal stance ought to be neutral. This objective would be met if measures were taken to secure a 0.5 percent of GDP deficit, but under the staff's weaker growth projection-while allowing the full play of fiscal revenue stabilizers beyond this point. On expenditures, the authorities acknowledged that slippages vis-à-vis the July's DPEF target for 2001 were accommodated by higher-than-planned expenditures in the 2002 budget. They intended to redress this issue forcefully in the context of future expenditure reforms.

\section{Structural Priorities to Enhance Growth}

\section{A substantial increase in Italy's long-term growth is inexorably linked to} improved labor market performance. The authorities, mindful of the very ambitious Lisbon summit targets for employment, planned to raise the traditionally low employment rate ( 53 percent in 2000 ) to 60 percent by 2006 . Already, several measures had been taken by the new government, including: making fixed-term employment contracts more flexible, in line with the EU directive; providing tax incentives on investment in buman capital (in the context of the Tremonti-bis); and fostering emergence of the informal economy. In addition, plans called for improving job matching by lowering constraints on private operators (e.g., temporary work and private placement agencies); facilitating use of atypical contracts; and raising the efficiency of labor market programs. In the staff's view, existing labor market policies, which absorbed resources exceeding 1 percent of GDP, were poorly targeted: while the South harbored two-thirds of the unemployed, with a youth unemployment rate of about 50 percent, only half of the positions supported under active labor market policies were located there, and less than a quarter included education and training support.

\section{While staff's call for greater wage differentiation for job seekers and among} regions was received coolly, other elements of staff's proposed partnership for skillstargeted at easing job-market entry-found more sympathy among the social partners. The view of some unions remains adamantly opposed to further wage differentiation. Although staff viewed it as facilitating job entry, learning-on-the job, and ultimately

${ }^{8}$ Aside from asset sales, some other budget items also have little demand effect. However, changes between 2001 and 2002 in these items are relatively small compared with asset sales. Netting-out asset sales from the calculation of the relevant structural balance is in line with the staff's treatment of UMTS receipts in euro-area countries (for Italy, see Table 1). 
successful labor market integration-was borne out, for example, by successful apprenticeship programs in several of Italy's partner countries-some labor representatives thought it would undernine existing bargaining structures and lead to wage competition toward the bottom. The staff's proposed partnership for skills (see SM/00/88, 3/15/00) included other elements that drew on proposals from the social partners: a commitment to improve job matching and training, especially for the young; and lower taxes and social contributions, focused on jobmarket entrants. Regarding dismissals, staff agreed that employment prospects could benefit from a more flexible arbitration mechanism, substituting for lengthy judicial proceedings.

\section{Accelerating development of the South formed a key plank of the authorities'} strategy, focused on upgrading its infrastructure. Building on progress achieved in recent years, they intended to reduce administrative and procedural investment requirements. A task force in the Ministry was studying ways to encourage private-sector participation (project financing). The staff welcomed these initiatives, but shared the view of most interlocutors that the task facing the South remained daunting - not least in view of remaining weaknesses in local administrative capacity and law enforcement. The capacity to attract private investment would also crucially depend on other reform steps, including in the labor market. The authorities acknowledged that progress in all these areas had often proved elusive in the past, but remained hopeful of making major inroads, in consultation with social partners.

\section{There has been broad progress on liberalizing product markets and promoting} competition, but international comparisons indicate considerable scope for further gains. The authorities expected progress from additional large-scale privatizations, targeted to yield about Lit 120 trillion (some 5 percent of 2000 GDP) over the next five years. In the electricity sector, the demand side of the market has been further liberalized. Even so, staff shared concerns by the regulatory authority and other observers that the ongoing divestiture by the dominant company may be insufficient to lead to a truly competitive market. The authorities are considering a full ownership split between electricity production and transmission, which could foster new investment and enhanced interconnectivity. Progress has been made in a range of other areas, including in moving toward more competitive pricing in the gas sector; unbundling of the local telephoneloop; and bolstering powers of the Antitrust Authority. There was general agreement that further gains could be made by streamlining regulations and more forcefully implementing past reforms at the local leveleffective entry restrictions for larger retail outlets and some liberal professions being two relevant examples.

33. In the banking sector, the authorities pointed to continuing gains in bank profitability and efficiency, but expressed some concern about a decline in riskweighted capital ratios (see Table 5). While the Bank of Italy was taking action to ensure a reversal of this decline, which resulted largely from robust lending growth, it also noted that concerns were somewhat alleviated by a level of household debt well below most partner countries, strong enterprise profitability, and indicators suggesting declining average risk in banks' lending portfolios. Bank efficiency, as measured by the ratio of costs to income, has improved over recent years through significant growth of income from asset management. 
But as this market matures, and competition intensifies, banks would need to manage costs more efficiently - and international comparisons suggested that ample scope remains. This also applied to nonperforming loans, whose ratio to total loans outstanding remained relatively high compared with partner countries, notwithstanding further declines in Italy's ratio (in part through securitization).

34. The discussions also covered nonbank financial market issues, and the supervisory framework. With respect to the future development of bond and equity markets, the authorities were concerned that the reluctance of owners to give up control and become more transparent might stymie increases in firm size. At the same time, the relative prevalence of smaller firms in Italy was difficult to attribute to specific market regulations or imperfections, and the authorities saw little need for policy intervention in this area. Both they and market participants stressed, however, that an area where reforms were needed was the efficiency of the judicial process and the bankruptcy law: among other things, a procedure analogous to Chapter XI of the United States code would facilitate more efficient management of nonfinancial enterprises in distress and shorten the time to resolve nonperforming loans. As regards consolidation in the financial sector, the Bank of Italy stressed, as a general view, that large banks should ensure that they had absorbed recent acquisitions before considering further mergers. But with growing links between banking and insurance, more formal links between the Bank of Italy and the insurance supervisor (ISVAP) had been established. On the changeover to the euro, no significant disruptions or macroeconomic effects were anticipated; the major concern was security of large currency shipments.

\section{Other Issues}

35. Italy has adopted the OECD's antibribery convention, and its efforts to combat money laundering were viewed by the Financial Action Task Force as consistent with its recommendations. On external trade liberalization, Italy remains a strong supporter of full trade liberalization vis-à-vis the least developed countries. Notwithstanding fiscal pressures, the new government intends to raise official development assistance, at 0.1 percent of GDP presently one of the lowest among industrial countries.

\section{Staff APPRaISAL}

36. Italy has made impressive strides in achieving deep-rooted macroeconomic stability, and in a range of areas structural reforms have been moving forward. Progress is clear in the continuing containment of inflation, owing much to the responsible behavior of labor unions; in the lower public debt ratio; in rising employment; and in reforms - from privatization to financial market liberalization-that have bolstered efficiency.

37. But growth has disappointed over the past decade-an issue highlighted by the present weakness in the global economy; and major fiscal challenges remain. Italy's recent growth record is one of the weakest among advanced economies-principally for 
deep-rooted structural reasons. Regional labor market imbalances are large; expectations of medium-term economic performance are low; and the economy has shown a lack of resilience in the present global slowdown. These features all speak to the need for structural change. In the fiscal domain, too, progress in ensuring a satisfactory path for the public debt is far from complete, and it will involve difficult choices in streamlining public spending.

38. Against this background, the government has laid out a bold agenda to reinvigorate growth. The broad focus of its program-on structural reforms in product and labor markets, as well as deregulation, public scctor reform, and fiscal adjustment-is welcome. And so is the emphasis on cutting the tax burden, particularly on labor income.

39. A number of important steps were taken during the government's first hundred days, in unexpectedly difficult circumstances. Faced with a testing combination of slowing growth and public spending slippages in its first months in office, the government has, among its early measures, achieved a key reforn of health care financing and fiscal arrangements with the regions, and launched the needed debate on pension reform. The issue of the 2001 budget deficit, too, was shrewdly navigated--bringing the headline figure down toward the Stability Program level, despite expenditure slippages and slowing growth, with expanded asset sales that avoided an undue shock to demand in the closing months of the year. Of course, as the economy enters a recovery phase, such financial measures will need to be substituted by a durable strengthening of the public sector's net asset position.

40. While the 2002 budget aims for the Stability Program's deficit target, its demand impact goes beyond the principle of allowing automatic fiscal stabilizers to operate. The budget reconfirms the Stability Program 's deficit target of 0.5 percent of GDP under circumstances of slowing growth. It relies extensively on asset sales, which have little or no demand effect; indeed, if the govemment's growth projection materializes, the demand impact of the budget would go beyond that of allowing automatic stabilizers to operate. Such fiscal support for activity is not advisable under likely growth outcomes for Italy, bearing in mind its high public debt. And the govermment's first expenditure targets, specified in July, were set aside only a few months later in the 2002 budget. This puts at risk the tax reduction agenda. Certainly, the case for a consultative approach on pension reform warrants some delay in the government's expenditure and taxation plans. But decisive action is needed in the coming months to establish a reform momentum.

41. Specifics of an expenditure and tax reform agenda should be laid out early-if not in the final version of the budget, then during 2002 - possibly taking advantage of the delegated powers sought by the government in areas such as pensions. Moving ahead with a well-specified reform agenda could help anchor expectations-particularly potent in the present environment of heightened uncertainty and weakened consumer and business confidence. The credibility this can give will be key for leveraging the benefits of policies that have a medium-term orientation, including achieving a near-term impact on investment and emergence of the underground economy. 
42. Along the same lines, adopting multiyear nominal expenditure ceilings could enhance the near-term credibility of policy, and facilitate the use of automatic fiscal stabilizers within the context of the Stability and Growth Pact. An explicit commitment to expenditure ceilings should be incorporated into updates of Italy's Stability Program; it would foster a more strategic approach to expenditure restraint. And, provided expenditure reforms are well specified, it would establish a benchmark for fiscal performance, while allowing revenue stabilizers to operate unfettered.

43. Regarding the goals underlying such medium- and long-run fiscal plans, the authorities' commitment to budget balance in 2003 remains appropriate on present indications for growth, and a move into surplus would be warranted in later years. With the current growth outlook, a balanced overall budget in 2003 implies a primary surplus above 6 percent of GDP. Given Italy's high public debt and aging population, this level of primary surplus should indeed be maintained into the future, resulting in an overall fiscal surplus. Once major entitlement and labor market reforms have been put in place, then the need for a surplus should certainly be reevaluated in light of the specifics of reforms. And over time, growth projections too may well be revised up as the impact of reforms becomes entrenched.

44. On tax reform, an effective medium-term strategy needs to be established-one that addresses the most severe distortions in the economy. Prudently, the govemment has determined to proceed with tax cuts only as required expenditure reforms are put in place to assure further fiscal consolidation. Still, room should be sought from spending reductions going beyond the 2002 draft budget, to make a start on deeper tax cuts even in 2002 -lest the commitment to tax and expenditure reduction be put into question. The benefits of reform will depend also on the design of tax cuts. Most importantly, this calls for cutting italy's high tax wedge on labor income-facilitating job market entry and the growth of the fornal economy. Plans for tax simplification, as envisaged by the government, could enhance efficiency; and, looking beyond the Tremonti-bis incentives, corporate taxation needs an efficient and stable framework, treating equitably different financing sources.

45. To make room for tax reductions that are both sizable and viable, expenditure reforms will need to be sustained over the medium term. The government's tax reduction plans-combined with a stable structural primary surplus-would require primary expenditures to decline by close to 1 percent of GDP per annum over the next five years. In this regard, reforms in all major expenditure categories, as intended by the authorities, are needed. To contain aging-related spending, a streamlining of seniority pensions and a reduction of disincentives to work are both required to raise the effective retirement age. And transition to the contribution-based system could be accelerated. Moreover, a much larger role should be allowed for private pension funds. On health expenditure, mechanisms are needed to make the delivery of services more efficient-with proper incentives, for consumers and providers, to contain expenditures on pharmaceuticals and other services. In this regard, consideration should be given to reintroduce better-targeted co-payments: The 
plans to extend cuts in public employment (taking advantage of attrition and redeployment), and to wind down subsidies and tax expenditures, are strongly welcome.

46. With the principle of fiscal devolution now established, control of the public finances will require strong commitment at all levels of government. The recent amendment to the Internal Stability Pact, covering regional health care spending, is a welcome step. Firm implementation of the Pact, including its amendment, will be critical; and the incentives for subnational governments to improve efficiency and avoid expenditure overruns need to be kept under active review-the more so, if devolution goes further.

47. A key to achieving more dynamic growth is to tackle the root causes of Italy's large regional imbalances and labor market weakness. No question, some progress has been achieved in the South in recent years-evidenced by faster growth of employment, investment, and exports in the formal economy. And the government's plan to facilitate enterprise entry from the informal into the formal economy could prove useful, provided it is seen as part of a credible strategy to reduce taxes and regulation over the medium term. However, unemployment rates in the South remain unacceptably high, especially among women and the young, and labor force participation nationwide is currently well below the level targeted by the Lisbon summit. It is hard to imagine a quantum change without increasing wage differentiation - both at the regional and job-entry level-to align wages more closely with productivity. This would also bring into the open some activities currently in the informal sector, where social protection is absent. Flanking measures are needed to facilitate job-market entry-including both tax cuts and improvements in training. Streamlined and better-targeted active labor market policies could also enhance performance, and at the same time save fiscal resources.

48. While the liberalization of product markets has been advancing, major scope remains to promote competition and efficiency, including at the local level. Italy still compares poorly in some areas with other advanced economies, and further privatization should be helpful. In the electricity sector, the benefits of partial liberalization could be enhanced by faster and deeper divestiture by the dominant firm. At the local level, a forceful streamlining of regulations and procedures-government priorities, indeed-is needed.

49. With regards to the financial sector, bank profitability and efficiency have continued to improve, but the authorities have rightly flagged a need for banks to raise risk-weighted capital ratios. Looking ahead, banks and borrowers alike would benefit from a more efficient judicial process, as well as a new bankruptcy law for nonfinancial corporations-which would strengthen the value of collateral and other legal contracts. The recent enhancement of supervisory cooperation in banking and insurance is warranted by market developments.

50. Italy provides adequate data to the Fund for survellance, notwithstanding weaknesses in several areas (Appendix II). On quarterly national accounts data, large revisions limit the informational content of initial estimates; and on inventory data, their non- 
separation from national accounts residuals hampers business cycle assessments. On general government data, weaknesses relate foremost to regional and local data, which have become more important with the trend to devolution; and to the collection and dissemination of quarterly data for the general government budget on an accruals basis. Some of these issues are to be addressed in a fiscal Report on the Observance of Standards and Codes-for which the authorities' request is welcome.

51. Italy's aim to raise official development assistance is laudable, as is its support for abolishing trade barriers for exports from the least developed countries.

52. It is proposed that the next consultation take place on the standard 12-month cycle. 
Table 1. Italy: Selected Economic Indicators, 1996-2002

(Percentage changes, except as otherwise indicated)

\begin{tabular}{|c|c|c|c|c|c|c|c|}
\hline & 1996 & 1997 & 1998 & 1999 & 2000 & $20011 /$ & $20021 /$ \\
\hline GDP & 1.1 & 2.0 & 1.8 & 1.6 & 2.9 & 1.8 & 1.4 \\
\hline Consumption (households) & 1.2 & 3.2 & 3.1 & 2.3 & 2.9 & 1.5 & โ.6 \\
\hline Public consurtption & 1.1 & 0.3 & 0,4 & 1.6 & 1.7 & 0.9 & $1 . \overline{5}$ \\
\hline Gross fixed investment & 3.6 & 2.1 & 4.3 & 4.6 & 6.1 & 1.4 & 2.6 \\
\hline Inventories (contribution) & -0.7 & 0.3 & 0.3 & 0.4 & -1.0 & -0.2 & -0.3 \\
\hline Foreign sector (contribution) & 0.2 & -0.6 & -1.2 & -1.3 & 0.6 & 0.7 & -0.1 \\
\hline Exports & 0.6 & 6.4 & 3.6 & 0.0 & 10.2 & 5.5 & 3.8 \\
\hline Imports & -0.3 & 10.1 & 9.0 & 5.1 & 8.3 & 3.4 & 4.3 \\
\hline Employment & 0.5 & 0.4 & 1.1 & 1.3 & 1.9 & 1.5 & 0.3 \\
\hline Consumer prices (period average) & 40 & 1.9 & 2.0 & 1.7 & 2.6 & 2.6 & 1.4 \\
\hline GDP deflator & 5.3 & 2.4 & 2.7 & 1.6 & 2.2 & 2.7 & 1.8 \\
\hline Output gap & -2.0 & -2.3 & -2.4 & -2.7 & -1.8 & $-1,9$ & -2.5 \\
\hline \multicolumn{8}{|l|}{ External accounts $2 /$} \\
\hline Export volume & 0.6 & 6.4 & 3.6 & 0.0 & 10.2 & 5.5 & 3.8 \\
\hline Import yolume & -0.3 & 10.1 & 9.0 & 5.1 & 8.3 & 3.4 & 4.3 \\
\hline Export utrit value & 0.3 & 0.1 & 0.6 & -0.5 & 6.8 & 1.3 & 0.4 \\
\hline Import unit vaiue & -1.9 & 0.5 & -2.6 & -0.5 & 13.6 & 1.6 & 0.0 \\
\hline Trade balance (in percent of GDP) & 4.4 & 3.4 & 3.0 & 1.7 & 1.0 & 1.4 & 1.4 \\
\hline Current account (in percent of GDP) & 3.2 & 2.8 & 1.7 & 0.5 & -0.5 & -0.1 & -0.1 \\
\hline Nominal effective exchange rate & 9.3 & 0.7 & -0.4 & -1.7 & -3.2 & $\ldots$ & $\ldots$ \\
\hline Structural prinary balance & 5.1 & 7.5 & 6.1 & 6,0 & 6.8 & 5.8 & 6.0 \\
\hline Of which: UMTS teceipts and asset sales & $\ldots$ & $\ldots$ & $\ldots$ & $\ldots$ & 1.2 & 0.2 & 0.7 \\
\hline Debt & 122.6 & 120.1 & 116.2 & 114.5 & 110.2 & 108.0 & 106.7 \\
\hline \multicolumn{8}{|l|}{ Financial variables } \\
\hline Contribution to euro area $M 36$ & $\ldots$ & $\ldots$ & 1.6 & 3.4 & 4.2 & 4.7 & $\ldots$ \\
\hline Total domestic credit $7 /$ & 5.2 & 3.5 & 3.7 & 6.3 & 6.1 & $\cdots$ & $\ldots$ \\
\hline Of which: To nonstate sector & 3.2 & 5.2 & 7.9 & 13.7 & 12.7 & $\cdots$ & $\ldots$ \\
\hline Six-month rate on treasury bills $8 /$ & 8.3 & 6.4 & 4.6 & 3.0 & 4.5 & 4.1 & $\ldots$ \\
\hline Prime tending rate 8 & 11.0 & 8.9 & 6.4 & 6.3 & 7.3 & 7.9 & $\ldots$ \\
\hline
\end{tabular}

Sources: Data provided by the Italian authorities; and Fund staff estimates and projections.

1/ Staff estimates and projections, unless otherwise indicated.

2/ Volumes and unit values are customs basis: trade balance and current account are balance of payments basis.

3/ Based on unit labor costs.

4/ For 2000, including UMTS receipts of 1.2 percent of GDP as a negative entry under capital expenditure; for 2001 and 2002 , including estimated receipts from asset sales of 0.2 percent and 0.7 percent of GDP, respectively, as a positive entry under capital revenue. 5/ For 2001 and 2002, part of the difference between these ratios and those reported in Table 2 are due to differences in nominal GDP projections. 6/ End-of-period data; data for 2001 refer to July; data break in 1998.

$7 /$ End-of-period data; data break in 1998.

8/ Period average; data for 2001 refer to August. 
Table 2. Comparison of Medium-Term Fiscal Plans

(Perusnt of GDP, except as otherwise indicated)

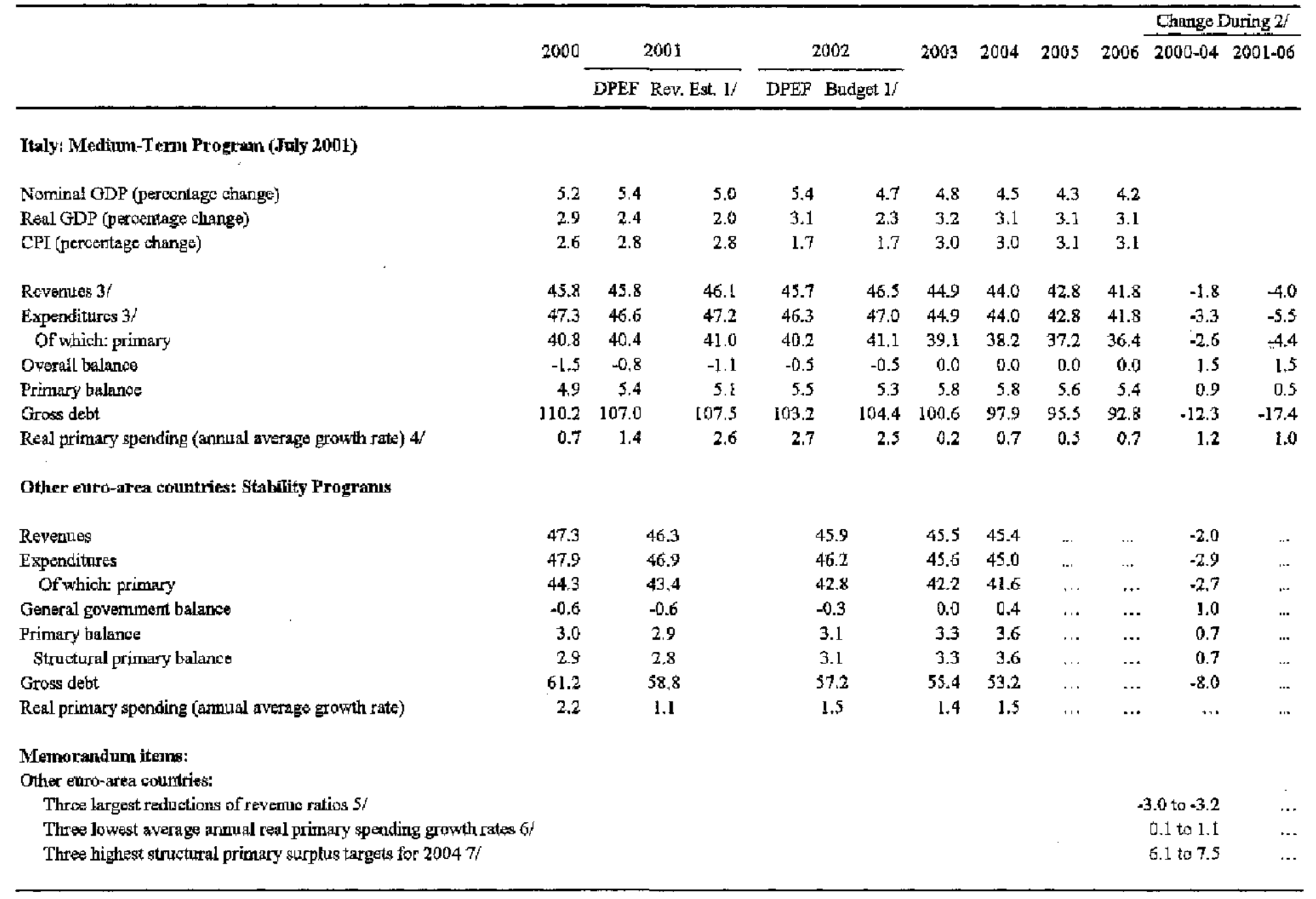

Sources: Documento di Programmazione Economica a Finanziaria (DPEF), July 200 1; Noto di Aggiornamento, August 2001; Reiczione Previsianale e Programmatica (RPP), Ostober 2001; EU Commission; and Fund staff calculations.

I/ Authorities' estimate for 2001 and draft budget for 2002 .

2/ For Ttaly, changes are based on DPEF targets.

3/ The 2002-06 DPEF program contains revenue data for current tax revenues and capital revemues only. Total revenues are calculated using a staff estimate for current nontax teuenue, based on the authorities' tendemaiale projection. Expenditures are caleulated as the difference between estimated total revemues and overail balance targets. Expenditures in 2000 exclude UMTS receipts.

4/ Nominal growth rate, deflated by the GDP deflator. For the last two columns, data refer to average growth rates over the respective periods.

5/ Fintand, the Netherlands, and Germany.

6/ Finland, Austria, and Germany.

$7 /$ Finland, Belgitum, and Ireland. 
Table 3. Italy: Adjustment Measures in the 2002 Budget 1/

\begin{tabular}{|c|c|c|}
\hline & $\begin{array}{c}\text { In millions } \\
\text { of euro }\end{array}$ & $\begin{array}{c}\text { In percent } \\
\text { of GDP }\end{array}$ \\
\hline Net revenue & 11,864 & 0.9 \\
\hline Additional tax receipts & 6,247 & 0.5 \\
\hline Tax on revaluation of equity holdings etc & 2,434 & \\
\hline Additional revenues generated by the expenditure measures & 1,433 & \\
\hline "Emergence" of underground economy and Tremonti-bis law & 1,033 & \\
\hline Abolishment of planned reduction in personal income tax rate & 831 & \\
\hline Lottery and games & 516 & \\
\hline Other receipts & 8,728 & 0.7 \\
\hline Sale of real estate assets & 7,747 & \\
\hline Capital repatriation & 981 & \\
\hline Tax reductions & $-3,111$ & -0.2 \\
\hline Tax and contribution reductions for job creation & $-1,170$ & \\
\hline Increase in personal income tax deductions for children & $-1,085$ & \\
\hline Other & -856 & \\
\hline Expenditures & 2,814 & 0.2 \\
\hline Cuts in current expenditures & $-3,603$ & -0.3 \\
\hline Cuts in transfers to local governments & $-1,549$ & \\
\hline Reductions in transfers and others & $-1,281$ & \\
\hline Reductions in public employment & -411 & \\
\hline Abolishment public entities & -362 & \\
\hline Increase in current expenditures & 5,663 & 0.4 \\
\hline Wage contracts & 3,159 & \\
\hline Higher minimum pensions & 2,169 & \\
\hline Overseas Development Assistance & 207 & \\
\hline Others & 128 & \\
\hline Support for private investment in infrastructure in the South & 754 & 0.1 \\
\hline Primary balance & 9,050 & 0.7 \\
\hline
\end{tabular}

Sources: Ministry of the Economy and Finance; and Fund staff estimates.

1/ On unchanged policies, the primary balance in 2002 would have reached 4.6 percent of GDP. As a result of the budgetary measures shown in this table, the primary balatice is programmed to reach 5.3 percent of GDP (see Table 2). 
Table 4. Italy: Fiscal Develepments Under Aitemative Scenarios 1/

(In percent of GDP)

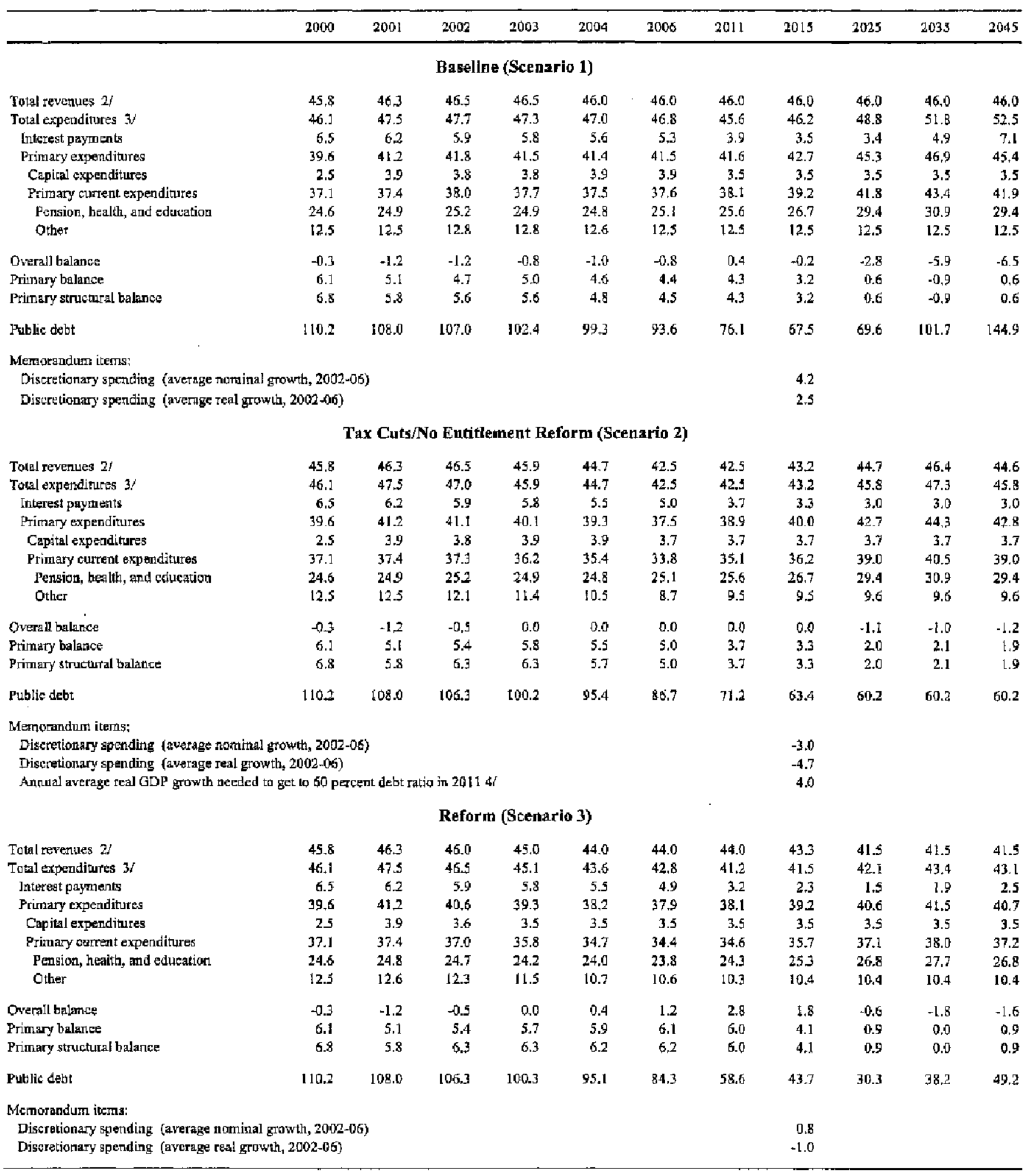

Source: Furd staff calculations.

1/ All scenarios assume the same real interest rate as well as real and nominal GDP growth rates. Beyond the WEO horizon, the real interest rate is assumed at 3.4 percent, infletion at 1.6 percent, and real GDP growth is assumed to declite gradually to zero by 2030 , consistent with censtant labor productivity growth of 1.2 percent per year and an increase in the ratio of employmant to the $20-64$ year-old population from some 57 percent to 62 perceat (see SM/99/115; $5 / 20 / 99$ ). $2 /$ Inchides estinated receipts from asset sales of 0.2 percent of GDP in 2001 and 0.7 percent of GDP in 2002 as capital reverue. 3/ Includes UMTS receipts of 1.2 percent of GDP in 2000 as negative capt:al expenditure.

$4 /$ Based on the same expenditure and tevenue tatios as shown in this scemario. 
Table 5. Italy: Indicators of External and Financial Vulnerability $1 /$

(In percent of GDP, unless otherwise indicated)

\begin{tabular}{|c|c|c|c|c|c|c|c|}
\hline \multirow[b]{2}{*}{. } & \multirow[t]{2}{*}{1996} & \multirow[t]{2}{*}{1997} & \multirow[t]{2}{*}{1998} & \multirow[t]{2}{*}{1999} & \multirow[t]{2}{*}{2000} & \multicolumn{2}{|l|}{2001} \\
\hline & & & & & & Latest est. & Date \\
\hline \multicolumn{8}{|l|}{ Exterual Indicators I/ } \\
\hline Exports (arnual percentage change, in U.S. dollars) & 7.5 & -3.2 & 0.9 & -5.7 & 1.3 & 3.6 & \\
\hline Imports (annual percentage change, in U.S. dollars) & 2.1 & 1.7 & 4.1 & -0.4 & 5.8 & 2.3 & \\
\hline Terms of trade (annual percentage change) & 4.0 & -1.1 & 2.3 & -0.5 & -6.0 & -0.3 & \\
\hline Current account balance (settlement basis) & 3.2 & 2.8 & 1.7 & 0.5 & -0.5 & -0.1 & \\
\hline Capital and financial account balance & -1.6 & .1 .4 & 0.5 & -0.6 & 0.5 & $\ldots$ & \\
\hline Of which: Inward portifolio investment (debt securities, enc.) & 6.1 & 6.3 & 9.4 & 8.9 & 5.3 & $\cdots$ & \\
\hline Inward foreign direct investment & 0.3 & 0.3 & 0.2 & 0.6 & 1.2 & $\cdots$ & \\
\hline Other investment liabilities (net) & 1.3 & 1.2 & 0.8 & 3.3 & 2.5 & $\cdots$ & \\
\hline Official reserves (in U.S. dollars, billions, end-of-period) $2 /$ & 45.9 & 55.7 & 29.9 & 22.4 & 25.6 & 26.0 & Jun. \\
\hline Contribution to euro area $\mathrm{M} 3$ (in percent of reserves) & $\ldots$ & 12.9 & 24.1 & 27.8 & 24.1 & 25.3 & Jun. \\
\hline Central Bank foreign liabilities (in U.S. dollars, billiong) 2/ & 1.2 & 1.1 & 1.0 & 6.3 & 0.2 & 1.2 & Jun. \\
\hline Foreign assets of the financial sector (in U.S. dollars, billions) & 214.5 & 198.5 & 225.1 & 175.4 & 187.4 & $\cdots$ & \\
\hline Foreign liabilities of the financiat sector (in U.S. dollars, billions) & 247.7 & 239.2 & 268.9 & 248.7 & 275.9 & $\ldots$ & \\
\hline Official reserves (tatio to average monthly imports) $2 /$ & 2.2 & 2.6 & 1.3 & 1.0 & 1.1 & ... & \\
\hline Total external debt & 53.5 & 59.0 & 71.2 & 72.8 & $\cdots$ & $\cdots$ & \\
\hline Of which: General govemment debt & 21.6 & 25.4 & 31.1 & 29.7 & $\ldots$ & 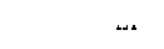 & \\
\hline Total external debt to exports (ratio) & 2.1 & 2.2 & 2.7 & 2.9 & $\ldots$ & $\cdots$ & \\
\hline External investment income payments to exports (in percent) & 16.8 & 18.0 & 19.9 & 19.0 & 16.4 & $\ldots$ & \\
\hline Exchange rate (per U.S. dollars, period atverage) & $1,542.9$ & $1,703.1$ & $1,736.2$ & $1,817.4$ & $2,101.6$ & $2,150.8$ & Aug. \\
\hline \multicolumn{8}{|l|}{ Financial Market Indicators } \\
\hline Public sector debt (Maastricht definition) & 122.6 & 120.1 & 116.2 & 114.5 & 110.2 & 108.0 & \\
\hline 3-month T-bill yield & 8.5 & 6.3 & 4.6 & 3.0 & 4.5 & 4.1 & Allg. \\
\hline 3-month T-bill yield (real) & 4.3 & 4.4 & 2.6 & 1.3 & 1.9 & 1.5 & Aug. \\
\hline Stock market index & 100 & 159 & 224 & 274 & 287 & 196 & Sep. \\
\hline Share prices of financial institutions & 100 & 171 & 265 & 275 & 337 & 220 & Sep. \\
\hline Spread of 3-tmonth T-bills with Germany (percentage points, period average) & 5.2 & 3.0 & 1.2 & 0.1 & 0.2 & 0.4 & hil. \\
\hline \multicolumn{8}{|l|}{ Financial Sector Risk Indicators } \\
\hline Foreign exchange loans (in billions of U.S. dollars) & 70.4 & 67.1 & 73.7 & 45.4 & 50.0 & $\ldots$ & \\
\hline Share of foreign exchange loans in total lending (percent) & 9.7 & 9.4 & 9.1 & 5.9 & 6.1 & $\cdots$ & \\
\hline Deposits in foreign exchange (in billions of U.S. dollars) & 23.0 & 24.1 & 25.8 & 21.8 & 22.3 & 11. & \\
\hline Share of foreign deposits in total deposits (percent) & 3.0 & 3.9 & 4.0 & 3.9 & 4.2 & $\cdots$ & \\
\hline Share of real estate sector in private credit & 7.2 & 7.6 & 8.4 & 9.8 & 11.6 & $\cdots$ & \\
\hline Share of nonperforming loars in total loans & 10.0 & 9.4 & 9.1 & 8.5 & 7.7 & $\ldots$ & \\
\hline Share of nonperforming loans in tomal assets & 4.0 & 4.0 & 4.3 & 3.6 & 3.3 & $\cdots$ & \\
\hline Risk-based capital asset ratio & 12.3 & 11.4 & 11.3 & 10.6 & 10.3 & $\cdots$ & \\
\hline Retuth on equity & 3.4 & 1.4 & 7.2 & 8.7 & 11.3 & $\ldots$ & \\
\hline Return on assets & 0.24 & 0.09 & 0.48 & 0.61 & 0.79 & $\cdots$ & \\
\hline
\end{tabular}

Sources: Bank of Italy, Ecanomic Bulletin and Statistical Bullefin; data provided by the anthorities; and IMF, International Financial Statistics.

1/ The interpretation of some indicators is affected by the launch of monetary union in 1999.

2/ Reserves and foreign liabilities refer to the Bank af Italy; both before and after EMU; excluding gold. 
ITALY: FUND RKLATIONS

(As of August 31, 2001)

I. Membership Status: Joined 3/27/47; Article VIII.

II General Resources Account:

Quota

Fund holdings of currency

Reserve position in Fund

Operational budget transfers (net)

SDR Million

$7,055.50$

$4,828.04$

Percent Quota

100.0

68.4

$2,227.46$

31.6

0.00

III. SDR Department:

SDR Million

702.40

Percent Allocation

Net cumulative allocation

252.56

100.0

Holdings

0.00

36.0

Designation Plan

IV. Outstanding Purchases and Loans: None

V. Financial Arrangements: None

VI. Projected Obligations to Fund (SDR Million; based on existing use of resources and present holdings of SDRs): None

VII. Exchange Rate Arrangement:

- Italy entered the final stage of European Economic and Monetary Union on January 1,1999 , at a rate of $1,936.27$ Italian lire per 1 euro.

- Italy retains restrictions vis-à-vis Iraq pursuant to UN resolutions, notified under Decision No. 144 (EBD/90/244, 8/13/90 and EBD/92/187, 8/28/92).

VIII. Article IV Consultations:

Italy is on the standard 12-month consultation cycle. The previous consultation discussions took place during March 2000 and the staff report (SM/00/88, 5/15/00) was discussed on June 5, 2000 (EBM/00/56). 


\section{ITALY: STATISTICAL INFORMATION}

Italy is subject to the statistical requirements and timeliness and reporting standards of the Eurostat and the European Central Bank (ECB). Economic data are provided to the Fund in a comprehensive manner (see attached table) and Italy has cooperated fully with the Fund in providing monetary, international reserves, and selected other financial statistics related to its membership in the European Economic and Monetary Union (EMU). These data are considered comprehensive, reliable, timely, and well documented.

Italy has subscribed to the Special Data Dissemination Standard (SDDS) and has posted the metadata for the Bulletin Board. In April 2000, Italy became the seventeenth country to be in full observance of the SDDS and to disclose enhanced international reserves data based on the format of the SDDS International Reserves Template approved by the IMF's Executive Board on March 23, 1999.

Overall, Italy's economic database is comprehensive and of generally high quality. However, several important weaknesses remain. First, initial quarterly national accounts estimates are subject to large revisions for at least two years. Accordingly, the informational content-particularly of the first data release-is relatively limited. Second, inventory accumulation is derived as a residual and lumped together with the statistical discrepancy: this hampers an analysis of the business cycle. Third, no quarterly data are available for the general government balance, expendifure, and revenue on an accruals basis in line with ESA95-requirements: as a result, it is difficult to precisely assess fiscal developments and policies during the year. And fourth, despite some improvements, the quality and timeliness of some fiscal data, particularly on expenditure by local governments, need improvement. 
Italy: Core Statistical Indicators

(As of end-September 2001)

\begin{tabular}{|c|c|c|c|c|c|c|c|c|c|c|c|}
\hline & $\begin{array}{l}\text { Exchange } \\
\text { Rates }\end{array}$ & $\begin{array}{c}\text { Iatcrnational } \\
\text { Reserves }\end{array}$ & $\begin{array}{l}\text { Centrat } \\
\text { Bank } \\
\text { Balance } \\
\text { Sheet }\end{array}$ & $\begin{array}{l}\text { Reservel } \\
\text { Base } \\
\text { Money }\end{array}$ & $\begin{array}{l}\text { Broad } \\
\text { Money }\end{array}$ & $\begin{array}{c}\text { Interest } \\
\text { Rates }\end{array}$ & $\begin{array}{l}\text { Consumer } \\
\text { Price } \\
\text { Index }\end{array}$ & $\begin{array}{l}\text { Exportsi } \\
\text { Imports }\end{array}$ & $\begin{array}{l}\text { Current } \\
\text { Account } \\
\text { Balance }\end{array}$ & $\begin{array}{c}\text { Overall } \\
\text { Government } \\
\text { Balance } 1 /\end{array}$ & $\begin{array}{l}\text { GDP } / \\
\text { GNP }\end{array}$ \\
\hline $\begin{array}{l}\text { Date } \\
\text { Received }\end{array}$ & $9 / 28 / 01$ & mid-July & $9 / 28 / 01$ & $9 / 28 / 01$ & $9 / 28 / 01$ & $9 / 28 / 01$ & $9 / 28 / 01$ & $9 / 28 / 01$ & $9 / 12 / 01$ & begin-Aug. & $9 / 20 / 01$ \\
\hline $\begin{array}{l}\text { Frequency of } \\
\text { Data }\end{array}$ & Daily & Monthly & Monthly & Monthly & Monthly & Daily & Monthy & Monthily & Monthly & Montbly & Quarterly \\
\hline $\begin{array}{l}\text { Frequency of } \\
\text { Reporting }\end{array}$ & Daily & Monthly & Monthly & Monthly & Monthly & Daily & Montbly & Monthly & Monthly & Monthly & Quarterly \\
\hline $\begin{array}{l}\text { Soturce of } \\
\text { Update }\end{array}$ & $\begin{array}{c}\text { Reuters, } \\
\text { Bloomberg }\end{array}$ & BoI, IFS & BoI & Bol, IFS & BoI & $\begin{array}{c}\text { Reuters, } \\
\text { Bloomberg }\end{array}$ & $\begin{array}{c}\text { ISTAT } \\
\text { Press } \\
\text { Release }\end{array}$ & $\begin{array}{c}\text { ISTAT } \\
\text { Press } \\
\text { Release }\end{array}$ & $\mathrm{Bol}$ & $\overline{\mathrm{UIC}}$ & $\begin{array}{l}\text { ISTAT } \\
\text { Press } \\
\text { Release }\end{array}$ \\
\hline $\begin{array}{l}\text { Mode of } \\
\text { Reporting }\end{array}$ & Electronic & Cable & $\begin{array}{c}\text { Internet, } \\
\text { Publication }\end{array}$ & $\begin{array}{c}\text { Internet } \\
\text { Publication }\end{array}$ & $\begin{array}{c}\text { Internet, } \\
\text { Publication }\end{array}$ & Electronic & Eiectronic & Electronic & Publication & $\begin{array}{l}\text { Internet, } \\
\text { Publication }\end{array}$ & Electronic \\
\hline $\begin{array}{l}\text { Confiden- } \\
\text { tiality }\end{array}$ & None & $\begin{array}{l}\text { Until data } \\
\text { off. released }\end{array}$ & None & None & None & None & None & None & None & None & None \\
\hline $\begin{array}{l}\text { Frequency of } \\
\text { Publication }\end{array}$ & Daily & Monthly & Monthly & Monthly & Monthly & Daily & Monthly & Monthly & Monthly & Monthly & Quarterly \\
\hline
\end{tabular}

1/ Central government on a cash basis. Overall government accounts are published once a year in February/March; the latest figure is for 2000 and was published March 1, 2001.

2/ Provisional estimate.

3/ Non-EU trade data were available through August 2001. 
Public Information Notice (PIN) No. 01/121

FOR IMMEDIATE RELEASE

November 20, 2001 international Monetary Fund

$70019^{\text {th }}$ Street, NW

Washington, D. C. 20431 USA

\section{IMF Concludes 2001 Article IV Consultation with Italy}

On November 5, 2001, the Executive Board of the International Monetary Fund (IMF) concluded the Article IV consultation with Italy. ${ }^{1}$

\section{Background}

Final domestic demand in Italy began to decelerate in the second half of 2000 , and economic weakness became more widespread by early 2001 . The initial deceleration in domestic demand reflected in part an unwinding of the stimulus from earlier declines in interest rates (related to adoption of the euro), as well as negative effects on households' disposable income of higher energy prices and terms of trade losses. Moreover, weaker external demand led to a sharp deceleration of exports and industrial activity by early 2001, and GDP growth stagnated in the second quarter. With relatively slow growth over much of the past decade, Italy's output gap is estimated by staff at around 2 percent, the highest in the euro area. Earlier pressures on headline inflation are abating: as energy prices reversed part of their earlier rise, harmonized consumer price inflation has begun to decline-to 2,6 percent (year-on-year) in September after a peak of 3.0 percent in April-and the positive differential relative to the euro-area average has been closed. Wage increases have remained moderate and eschewed spillovers from higher import prices, especially in the private sector. Wage restraint has supported employment growth, and the unemployment rate fell to 9.2 percent in July from 10.1

\footnotetext{
${ }^{1}$ Under Article IV of the IMF's Articies of Agreement, the IMF holds bilateral discussions with members, usually every year. A staff team visits the country, collects economic and financial information, and discusses with officials the country's economic developments and policies. On return to headquarters, the staff prepares a report, which forms the basis for discussion by the Executive Board. At the conclusion of the discussion, the Managing Director, as Chairman of the Board, summarizes the views of Executive Directors, and this summary is transmitted to the country's authorities. This PIN summarizes the views of the Executive Board as expressed during the November 5, 2001 Executive Board discussion based on the staff report.
}

Washington, D.C. 20431 - Telephone 202-623-7100 - Fax 202-623-6772 - www.imt.org 
percent a year earlier. Still, demographic and regional imbalances in the labor market remain pervasive, with unemployment much higher in the South and among women and the young.

In 2000, further progress was made on fiscal consolidation-the general government deficit met the targeted 1.5 percent of GDP, and public debt declined in relation to GDP to 110 percent. For 2001, however, achieving the deficit target of 0.8 percent will be difficult in light of sizable expenditure overnuns, especially on health care expenditures and wages. At the same time, nominal revenues are expected to meet budget targets, reflecting improved tax administration and buoyant direct tax revenues.

In light of the worldwide economic slowdown and potential repercussions from the September 11 terrorist attacks, prospects for a recovery in the near term have dimmed. Staff expects GDP growth to be limited to 1.8 percent in 2001 and to 1.4 percent in 2002 . These projections are, however, subject to considerable uncertainty, not least related to the unfolding of the fallout from the September attacks. On the downside, confidence could deteriorate sharply, lowering domestic demand, especially for investment and consumer durables; and external demand could also weaken more than currently anticipated. On the upside, monetary easing and lower oil prices could trigger a more robust recovery. As discussed in the Executive Board assessment below, the outlook for growth over the medium term will depend crucially on the pace of structural reform in general, and on further increases in labor-force participation in particular.

\section{Executive Board Assessment}

Executive Directors commended the authorities for achieving macroeconomic stability, containing inflation, reducing unemployment, lowering public debt, and moving structural reforms forward in a number of areas. However, Directors noted that Italy's recent growth performance was among the weakest for industrial countries and that major fiscal and structural challenges remain. Against this background, they welcomed the authorities' intention to undertake reforms aimed at reinvigorating growth and strengthening the public finances. In particular, Directors highlighted the need to reduce the tax burden, especially the tax wedge on labor; to mitigate the fiscal impact of population aging; and to further improve labor and product market performance. They encouraged the authorities to implement this reform agenda quickly and decisively, although several Directors also underlined the desirability of building a broad consensus, especially in the current unsettled environment.

Directors considered the near-term economic outlook to be fraught with uncertainty, given the present global slowdown. Notwithstanding recent monetary easing by the European Central Bank, which would be supportive of a recovery in activity, they viewed monetary conditions as remaining somewhat tight from a purely domestic perspective, noting Italy's large output gap and abating inflationary pressures. They considered external competitiveness as broadly satisfactory at present.

Directors viewed favorably the reduction in the budget deficit in 2001, despite weaker than expected real growth, although they regretted that primary expenditure had again exceeded 
the budget targets. They welcomed Italy's intention to live up to its Stability Program commitments in 2002 and 2003. Many Directors expressed concern, however, that underlying adjustment in 2002 was being postponed, with deficit targets to be met through asset sales implying that the fiscal support to economic activity would go beyond the operation of automatic stabilizers. Directors discussed the authorities' plans to handle these asset sales through a new financial vehicle, and recommended caution in the use of this instrument. They recognized that such sales might qualify under the Stability and Growth Pact as deficitreducing, but urged the authorities to focus on a durable reduction in public expenditure. They also considered that asset sales should be recorded rigorously.

While letting the automatic stabilizers operate on the revenue side was viewed as appropriate, most Directors saw little scope for discretionary fiscal policy to support aggregate demand, given the high public debt. A few Directors, however, considered this fiscal stimulus appropriate, in view of the weaknesses in economic activity. Directors endorsed the objective of a balanced budget by 2003 .

Beyond 2003, Directors recommended adoption of a fiscal strategy that would decisively reduce Italy's still high public debt ratio, thereby avoiding the need for an increase in tax rates around the demographic peak. Directors considered that such a strategy would call for achieving and maintaining a structural primary surplus somewhat above 6 percent of GDP for the rest of the decade, a more ambitious target than implied by the broadly balanced overall budget indicated in Italy's Stability Program and in the authorities' medium-term plans.

Directors emphasized that the twin objectives of reducing both the deficit and the tax burden will require tight limits on the growth of public expenditure. In this regard, they welcomed the government's plans to reduce public employment, taking advantage of attrition and redeployment, and saw scope for winding down subsidies and tax expenditures. On social spending, Directors welcomed the progress achieved with earlier pension reforms, but stressed the need for further steps to limit the budgetary impact of population aging, and to rebalance spending from pensions toward programs that support labor market integration and the poor. Further pension reform could include a faster increase in the effective retirement age, an acceleration of the transition to a contribution-based system, and allowing a large role for private pension funds. Directors welcomed the recent agreement with the regions aimed at containing health expenditure, and stressed the need to make the delivery of health services more efficient and to contain expenditures on pharmaceuticals. They recommended the adoption of multi-year nominal expenditure ceilings, which could enhance the near-term credibility of fiscal policy, while allowing automatic stabilizers on the revenue side to operate unfettered.

On tax policy, Directors saw the need to establish an effective medium-term strategy, addressing the most severe distortions in the economy first, in particular the high tax wedge on labor income, which discourages labor participation and employment. However, the scope for tax reform will depend critically on implementation of durable expenditure reforms. Several Directors cautioned against using overly optimistic growth assumptions in medium-term budget 
projections. A few Directors also expressed reservations about the recourse to temporary tax incentives.

Directors welcomed the signs of improved economic performance in the South, as evidenced by faster output and employment growth, but regretted the persistence of very large regional imbalances. They emphasized that reduction of these imbalances will depend on improving labor market performance along several dimensions: the most important and urgent is to foster broad and productivity-based wage differentiation, but Directors also recommended the authorities to adopt additional measures to facilitate job-market entry, specifically for the young (including tax cuts and improvements in training); and to streamline and better target active labor market policies. They viewed the government's plan to facilitate enterprise migration from the informal to the formal economy as a useful step, provided it is accompanied by a credible strategy to reduce taxes and regulation over the medium term. Directors also stressed that further product market liberalization and privatization, along with efforts to strengthen local administrative capacity and law enforcement and to simplify administrative and procedural requirements for the setting up of businesses, will help spur investment in disadvantaged areas.

Directors welcomed the improvements in bank profitability and efficiency, and supported the authorities' call for banks to raise their risk-weighted capital ratios. They underlined the importance of reducing operating costs, and pointed to the potential benefits-for banks and borrowers alike - of a more efficient judicial process and a new bankruptcy law for nonfinancial corporations.

Directors welcomed Italy's aim to raise official development assistance toward the UN target and the authorities' policy objective of abolishing all EU barriers for exports from the poorest countries.

Italy provides adequate data for surveillance purposes. In view of the need to further improve some of the data, Directors welcomed the authorities' request to prepare a ROSC module on fiscal transparency, and, more generally, welcomed the intention to undertake several other ROSC modules.

Public Information Notices (PINs) are issued, (i) at the request of a member country, following the conclusion of the Article IV consultation for countries seeking to make known the views of the IMF to the public. This action is intended to strengthen IMF surveillance over the economic policies of member countries by increasing the transparency of the IMF's assessment of these policies; and (ii) following pollay discussions in the Executive Board at the decision of the Board. The Staff Report for the 2001 Article IV Consultation with Italy is also available. 
Italy: Selected Economic Indicators

\begin{tabular}{|c|c|c|c|c|}
\hline & 1998 & 1999 & 2000 & $2001 / 1$ \\
\hline \multicolumn{5}{|l|}{ Real economy (change in percent) } \\
\hline GDP & 1.8 & 1.6 & 2.9 & 1.8 \\
\hline Domestic demand & 3.1 & 3.0 & 2.3 & 1.2 \\
\hline CPI & 2.0 & 1.7 & 2.6 & 2.6 \\
\hline Unemployment rate (in percent) & 11.8 & 11.4 & 10.6 & 9.5 \\
\hline \multicolumn{5}{|l|}{ Public finances (general government; in percent of GDP) } \\
\hline Overall balance $2 /$ & -2.8 & -1.8 & -0.3 & $-1,2$ \\
\hline Primary balance $2 /$ & 5.2 & 5.0 & 6.1 & 5.1 \\
\hline Gross debt & 116.2 & 114.5 & 110.2 & 108.0 \\
\hline \multicolumn{5}{|l|}{ Money and credit (end of year, percent change) } \\
\hline Contribution to euro-area M3 $3 /$ & 1.6 & 3.4 & 4.2 & 4.7 \\
\hline Total domestic credit & 3.7 & 6.3 & 6.1 & $\ldots$ \\
\hline \multicolumn{5}{|l|}{ Interest rates (year average) } \\
\hline Six-month rate on treasury bills & 4.6 & 3.0 & 4.5 & 4.1 \\
\hline Government bond rate, ten-year & 4.9 & 4.7 & 5.6 & 5.0 \\
\hline \multicolumn{5}{|l|}{ Balance of payments (in percent of GDP) } \\
\hline Trade balance & 3.0 & 1.7 & 1.0 & 1.4 \\
\hline Current account & 1.7 & 0.5 & -0.5 & -0.1 \\
\hline \multicolumn{5}{|l|}{ Fund position (as of August 2001) } \\
\hline Holdings of currency (in percent of quota) & \multicolumn{4}{|c|}{68.4} \\
\hline Holdings of SDRs (in percent of allocation) & \multicolumn{4}{|c|}{36.0} \\
\hline Quota (in millions of SDRs) & \multicolumn{4}{|c|}{$7,055.5$} \\
\hline \multicolumn{5}{|l|}{ Exchange rate } \\
\hline Exchange rate regime & \multicolumn{4}{|c|}{ EMU member } \\
\hline Present rate (October 15,2001 ) & \multicolumn{4}{|c|}{ US $\$ 0.910$ per auro } \\
\hline Nominal effective exchange rate 4 / & -0.4 & -1.7 & -3.2 & 0.3 \\
\hline Real effective exchange rate based on unit labor cost 4 / & -1.9 & -0.3 & -3.2 & -0.7 \\
\hline
\end{tabular}

Sources: Data provided by the Italian authorities; International Financial Statistics; and IMF staff estimates and projections.

1/ IMF staff estimates and projections.

2/ For 2000, including UMTS receipts of 1.2 percent of GDP. For 2001, including estimated receipts from asset sales of 0.2 percent of GDP.

$3 /$ For 2001, year-on-year change for July.

4/ For 2001, based on monthly average to August. 


\section{Statement by Pier Carlo Padoan, Executive Director for Italy November 5, 2001}

\section{The challenge ahead: stability, growth, and equity}

1. At the outset I would like to thank staff for their extremely useful work during this consultation. They have provided an insightful analysis and laid out the framework for the policy choices the government is making at the beginning of its mandate. Over the past five years Italy has achieved financial and price stabilization. With a clear mandate to govern the country for a full legislature, the challenge ahead for the newly elected coalition is to preserve financial stability; increase the potential for output and employment growth. especially in the Southern regions; and ameliorate the distribution of income, within and across generations, in ways consistent with incentives to growth. These objectives will be achieved by complying with the EU fiscal rules; streamlining the role of the state in the economy; developing infrastructure, technology, and human capital; reforming the labor and products markets; and reducing taxes.

\section{A necessary precondition: fiseal discipline}

2. The government has reaffirmed Italy's commitment to the process of economic adjustment agreed upon with EU partners. The respect of the fiscal guidelines set by the Stability and Growth Pact (SGP) remains the pillar of Italy's macroeconomic policy. As much as they inform the government's short-term action, the guidelines also underpin the medium-term strategy and define the financial compatibilities within which trade-offs will be evaluated and choices made. The reform programs that will be implemented during the legislature and the associated expenditure plans will thus be conditional on the compliance with the SGP targets.

\section{The short-term outlook}

3. The September 11 events have led to maior downward revisions of the growth perspectives for 2001 and 2002, much in line with revisions for other EU countries Revised staff estimates indicate lower growth for 2001 and, especially, for 2002 , for which projected growth is below 1.5. What is worrying about such a scenario is not so much the downward revision but, especially, the deceleration of growth in 2002 that, according to staff estimates, is entirely due to a strong deceleration in exports, leading to a negative contribution of the foreign sector. This effect is somehow surprising given that in the past Italy has been exposed less than other major EU countries to negative shocks from the industrialized area and that the "new" transmission mechanisms through expectations and financial channels are also less powerfil, On the contrary, all other demand components are seen to be on the rise. Given the still very high degree of uncertainty surrounding the current situation my authorities maintain that growth estimates for 2002 remain on the rise (see the update to 
DPEF, "Nota di Aggiornamento," issued on October 29) and wait to evaluate the consequences of September 11.

4. Abstracting from this component, some of the factors responsible for the slowdown beginning in the second half of 2000 , such as higher oil prices, were beginning to change direction in the second half of the current year, while export shares were reverting a long declining trend. Assuming the projected acceleration of machinery and construction. investment in 2002 , as well as continuing wage moderation that will preserve competitiveness, a pick-up of growth next year could still represent a plausible hypothesis. Recent data are, in this respect, somewhat encouraging.

5. While it is true that business confidence indicators have dropped, they also reflect the fact that firms have chosen to "wait and see" from the perspective of the new fiscal measures, in particular the major tax reform package due by the year end. More recent surveys indicate that manufacturing firms see the situation as "uncertain," but they also see signs of moderate optimism. Recently released consumer confidence indicators indicate no substantial change in households' attitude after the September events.

6. VAT revenues in October increased by 2 percent with respect to October 2000. Social security contributions rose 6 percent over the same period, pointing at substantial employment increases on top of an already significant employment growth. It would be surprising if this were not associated with better output performance.

7. That said, 2002 will see lower growth, in Italy as almost everywhere, with respect to previous forecasts. Lower growth will bring a lower speed in the implementation of reforms. Nonetheless, the budget will generate in 2002 changes in the right direction as the primary surplus will increase, interest payments will decrease, and the overall balance will meet the 0.5 target. These results are expected by the government, assuming very conservative estimates for the revenues from "emersione" of the underground economy and from capital repatriation measures.

\section{The longer-term trade-offs}

8. The Staff Report contains a very useful discussion of the long run trade-offs for fiscal policy. The comparison between the baseline, the "tax cuts/no entitlement reforms," and the "reform" scenarios confirm what one might have suspected about the long-run preferability of reforms. The scenario exercises are clearly illustrative but, by providing benchmarks, they do help, together with the discussion in the text, to clarify the options that the government is facing in the medium term.

9. As for all simulations, the scenarios rely on specific assumptions that may lead to different pictures once they are changed. One factor to which these exercises are highly sensitive is the projected rate of growth. As Box 1 recognizes different assumptions on growth (as adopted for instance in studies by the Treasury in the framework of an OECD exercise) would lead to different results in terms of pension sustainability. So, to make these 
exercises more useful, one should try to incorporate the feedback on growth of the announcement and implementation of reforms; and the effect on growth of related measures such as, for example, those aimed at supporting employment.

10. This said, the report does provide a clear analysis of the trade-offs the government is facing. The definition of the medium-term strategy is currently under way. The following points, however, can already be set out.

- Raising the growth rate significantly and permanently and the employment content of growth remains at the center of the medium-term strategy.

- The budget will balance by 2003 and will move into surplus in 2005 at the latest, leading, according to Treasury calculations, to an improvement of the structural balance.

- While keeping to its fiscal commitments, the government, starting in 2003, will reduce the overall fiscal pressure by bringing it down from 41.5 percent in 2003 to 38.2 percent in 2006 . The tax rate structure will be simplified, and the highest tax rates on personal and corporate incomes will be reduced significantly.

- Expenditures will be put under strict control starting from 2001, and will decline by 4 percentage points over $2002-06$.

- The fiscal burden will be redistributed in a more equitable way by introducing exemptions for larger families and for lower-income groups. Social security contributions will be reduced, and minimum pensions will be raised from 2002 onward, starting with the elder and more vulnerable beneficiaries.

11. The cutrent slowdown requires postponing by one year the implementation of a new fiscal reform in addition to the temporary measures introduced by the 2002 budget. The implementation of key reforms in pensions and the labor market will start after consultation with the social partners, which has recently begun, is completed. This consensus building exercise will provide the credibility for the reform process and generate positive externalities on other measures, such as those related to the emersion of the underground economy, by providing credibility to the tax-cut plans. Finally, important results have already been achieved in health expenditure control following recent agreement with the regions.

\section{Boosting growth potential and narrowing the regional gap}

12. Raising Italy's low rate of growth as well as its employment content is key in the government's medium-term strategy. As mentioned in this Chair's BUFF in 2000, low growth is to blame on high taxes on labor and a generally high tax burden, and on other factors as well, such as a limited contribution of total factor productivity due to both a 
relatively low propensity to innovate (as measured by standard innovation indicators) and to lacking infrastructure. In addition, the low growth performance for the economy as a whole clearly reflects the performance gap between North and South..

13. Italy's disappointing growth rate would significantly be lifted by the catching-up of the Southern regions to higher Northern values. Evidence for the late 1990 s suggests that catching-up has already begun. The latest available data show that, between 1997 and 1999 , the Mezzogiorno has grown faster than the rest of the country (2.7 percent versus 1.8 in $1997,2.1$ percent versus 1.7 in $1998,1.8$ percent versus 1.6 in 1999). This calls for growthboosting measures that are targeted at both national and regional dimensions. Labor tax cuts, measures to encourage entry of youth and women in the workforce, as well as continuing wage moderation, will benefit the whole economy. Measures for the "emersione" as well as wage-setting mechanisms that better reflect differences in productivity will sustain growth and employment in the lagging regions. The White Book ("Libro Bianco") on employment and social issues, recently released by the government, represents a promising base to set out the strategy both at the national and the regional level.

\section{A smaller state, a more efficient state}

14. A smaller and more efficient public administration supports growth potential both by decreasing pressure on domestic resources and by helping markets work better. Moves to achieve this target include measures in the 2002 budget towards the containment of public expenditure through enrollment freeze, employment reductions, and improvements of costcontrols and procurement rules; the suppression of redundant state agencies and the transformation of others into non-profit private sector companies; the divestiture of large chunks of state-owned reaI estate assets; and the reorganization of public services provision through decentralization, wider office-automation, and outsourcing to the private sector. Strong emphasis is placed on the simplification of administrative and procedural requirements on enterprises, building on initiatives undertaken in the late $1990 \mathrm{~s}$, and on the adoption of an up-to-date information infrastructure to better link public administration and the private sector.

15. Privatizations in the energy, transportation, and telecommunication sectors, for a total of euro 60 billion worth of assets over the legislature will add to the process of state retrenchment from the economy. Privatization of the main electricity company will be accelerated provided that market conditions are appropriate.

16. The government will further the process of fiscal devolution that Italy initiated in the early $1990 \mathrm{~s}$, both on grounds of economic efficiency and in response to demands for regional decentralization of fiscal responsibilities. Local administrations have been granted higher spending and taxation authority, as well as larger entitlements to national fiscal revenues, with a view both to connecting more closely the provision of local services to the needs of local users and to linking spending decisions and financing responsibilities more tightly. The implementation and the strengthening of the Internal Stability Pact will exert discipline on 
local administrators by requiring them to correct excess deficits with spending cuts, tax increases, or new borrowing.

\section{Improving infrastructure, deepening technology, expanding knowledge}

17. A smaller state will make room for a more effective public action on infrastructure development. The "Legge Obiettivo" takes into account that considerable investment is needed in the hydro-geologic, water, and transportation systems, with large works to be undertaken especially in the South and in the other laggard areas. Financing will be made available from budget savings and from private sector resources through project financing.

18. The government intends to increase in the medium term the public $R \& D$ expenditure-toGDP ratio to match the level prevailing in the rest of the EU, adopting transparent and meritbased criteria for allocating public resources. Great importance is given to the creation of a new patenting system, which will better protect the intellectual property rights of innovators. This, combined with venture capital money, is expected to spur research initiatives.

19. On information and telecommunications, the government will launch a five-year plan to develop a cross-country, wide-band system for the expansion of internet; it will support the full liberalization of telecommunication services, and will implement a program to expand the use of IT in the public administration and in schools.

20. Education ranks high on the government's list of priorities. As the limits on public sector enrollment and employment will extend to the school system, spending will be redirected from wages to teacher training programs and the diffusion of multimedia technologies in classrooms. Overall, the state will compete with the private sector in carrying out direct school managerial responsibilities, while it will define overall education policies and quality standards. The reform will also improve the supply of higher education services.

\section{Making labor markets more efficient}

21. As mentioned, the "Libro Bianco" lays out the basic principles for improving employment performance. The government plans to raise the employment rate to 59 percent by 2006 (from 53 percent in 2000). Such a target is to be interpreted as a first step in the framework of the Lisbon strategy, the target of which, for the EU as a whole, is 70 percent in 2010. Both measures that favor economic growth prospects, particularly in the South, and measures aimed at increasing the employment intensity of growth and favoring employment prospects of youths, women and elderly people are envisaged. Measures will concentrate upon further easing the use of part-time and "atypical" contracts to facilitate market entry, especially for the young and for women. In doing that, attention will be paid to the existing set of regulations so as to avoid the risk of labor market segmentation between atypical and typical. Rules and controls will be simplified for private job-market intermediaries, while 
aiming at market transparency through the set-up of an interconnected information system ("Sistema Informativo del Lavoro") on supply and demand.

22. Employment incentives will be simplified and better targeted. Under these respects, the Libro Bianco further hints at the possibility of experimenting with in-work benefits for lowincome people, so as to allow also for a wider wage differentiation and incentives to the female labor supply. A gradual shift is also envisaged from the traditional rather strict on-thejob protection system, benefiting insiders, to more efficient in-the-market guarantees for all workers, through a better integrated design of active and passive labor market policies. The timing of such a shift is connected to the actual prospects of pensions' expenditure, the dimension of which still limits the room for social contributions cuts and/or redirections.

23. Finally, wage setting mechanisms should be improved to take into account the productivity differential. This should significantly reduce the employment differential between North and South. The unemployment rate, which has decreased one percentage point to 9.4 in July 2001 with respect to the same month in 2000 for the country as a whole, amounted to 3.9 percent in the North and 19.1 percent in the Mezzogiono.

\section{Expenditures: declining amounts, better quality}

24. The medium-run target for expenditure decline affects all the main items: public sector employment, health and pensions. With regard to public sector employment, the government's principles of streamlining and raising the efficiency of public administration are embodied in the 2002 budget. In this regard, strict limits will be imposed to public sector hiring, that will be de facto frozen in 2002, and will lead to a decline by at least 1 percent of the workforce in 2003 and 2004 . Furthermore, public procurement will be centralized and rationalized.

25. Health expenditure, which makes up for the largest share of the expenditure at the decentralized levels of government, will be contained thanks to a recent agreement with the regions, which complements in an essential way the devolution reforms of the previous years. The agreement, which covers the entirety of the financial relations between the state and local governments, sets a guideline of a 4.5 percent nominal growth in 2002 expenditures of the regions. The increase in transfers to regions acknowledges the systematic ex ante underfunding of health expenditures by the central government. At the same time, the regions' entitlement to the transfers from the central government is made conditional on their systematic reporting and monitoring of expenditures, their participation in a centralized procurement system, and their provision of minimum levels of health care defined on a national basis. Most importantly, the centerpiece of the agreement is represented by the principle of accountability for expenditure overshooting compared to the predetermined targets. Local administrations will be solely responsible for their financing through increases in local taxes, expenditure cuts, or borrowing. 
26. The government is currently considering a review of the pension system through the build-up of support of social partners, including trade unions and business associations. The results of a report by a commission appointed by the Ministry of Labor ("Commissione Brambilla") confirm the need for reform. In the absence of corrective measures, the report projects pension expenditures as an increasing share of national GDP in the coming years at least through 2030 , when they will reach 16 percent. Indeed, the present set up suffers serious weaknesses, in particular in the relatively slow phasing in of the contribution-based system, the still very low average retirement age, and the limited role of private pension plans. The government is committed to a reform of the system, relying on the principles of safeguard of existing entitlements and freedom of choice of private or public pension plan. The reform process will however be delicate, due to the extensive social stakes in play. It is worth noting that the government, in the 2002 budget, has increased the level of minimum pensions for seniors to around 500 euros per month. This amount constitutes the only increase in expenditures in terms of GDP in the area of pensions in the budget.

27. Capital expenditure accelerated in 2001 compared to 2000 , and will further increase in 2002 and the following years. Public investment will be concentrated in infrastructures, especially in the South. As mentioned, this program will rely extensively on private sector participation through project financing, which will amount to half the financial resources needed for the ambitious investment plan. The importance given to this area of action is underlined by the layout of a framework law for public investments as part of the initiatives for the "first 100 days" of the government.

\section{Reducing and simplifying the tax burden}

28. A comprehensive tax reform proposal will be presented by year-end with the aim of reducing fiscal pressure slightly in 2002 and at an accelerating pace starting in 2003 . To this end, the government envisages the reduction in the number of taxes from the current one hundred to only eight. In the same vein, the more than three thousand fiscal norms will be rationalized into one comprehensive fiscal code.

29. The new "Tremonti Law" has introduced incentives for investment decisions while simplifying the procedures. With respect to similar measures adopted in 1994 it has widened the range of eligible beneficiaries including -- in addition to manufacturing firms -- banks, insurance companies and the self-employed. It has also widened the range of investments falling under the new scheme, comprising investments in fixed capital as well as in human capital. Such measures, which were introduced last July, are expected to be in place until December 2002. In addition the government has reintroduced the norm allowing for the revaluation of assets for firms (introduced in 2000) and has extended it to other items such as land property.

30. The authorities see these measures as temporary. They envisage a far-reaching reform on business taxation bringing down the rates on corporate incomes to 33 percent from the 
current 36 percent, while at the same time simplifying and making more effective the related procedures for tax compliance while affecting permanently the cost of capital.

31. On personal income taxation, the authorities plan to reduce and simplify the current framework, by adopting only two tax rates, namely 23 percent on incomes up to around euro 100,000 and 33 percent for incomes above this amount.

32. As noted, the tax wedge in Italy ranks high with respect to other OECD countries and reduces the hiring incentives for firms while discouraging workers to actively seek a job or even to enter the labor force. To this purpose, the government plans to reduce the wedge by decreasing social security contributions by roughly one percentage point per year over the next five years.

\section{Conclusions}

33. At the conclusion of last year's Art. IV discussion this chair pointed out that sound macroeconomic policies and structural reforms were beginning to bear fruits and that pressing ahead with the reform agenda was essential. The global slowdown, precipitated by the September 11 events, has certainly made the environment for reforms more difficult in Italy, an environment where business expectations were pointing at an upcoming acceleration of growth above what was expected in other major EU countries. Notwithstanding the current uncertainty, my authorities remain strongly committed to push ahead with their anbitious, yet indispensable, program, as they believe that credible reform plans will provide a positive shock on confidence that will push the economy away from the risk of falling into an "expectation trap." 